\title{
Nonlinear free vibration of cylindrical shells with delamination using high order shear deformation theory:-A finite element approach
}

\author{
Asst. Prof. Dr. Nabil Hassan Hadi and Kayser Aziz Ameen
}

\author{
Dept. of Mech. Eng. College of Engineering University of Baghdad, Baghdad- Iraq, \\ nabilhha@yahoo.com \\ kayseraziz@yahoo.com
}

\begin{abstract}
A dynamic analysis method has been developed to investigate and characterize embedded delamination on the dynamic response of composite laminated structures. A nonlinear finite element model for geometrically large amplitude free vibration intact shallow cylindrical and delamination shell analysis is presented using higher order shear deformation theory where the nonlinearity was introduced in the Green-Lagrange sense. The governing equation of the vibrated shell were derived using the Variational approach. The effect of different orthotropicity ratio, and delamination size on the non-dimenational fundamental frequency and frequency ratios of plate for different stacking sequences. Finally the results were compared with those available in literatures where the discrepancy of the results was $(15.8022 \%$ with considering the nonlinearity).
\end{abstract}

Keywords: Delamination, High order shear deformation, Shell, Free vibration, Nonlinear Finite element Method.

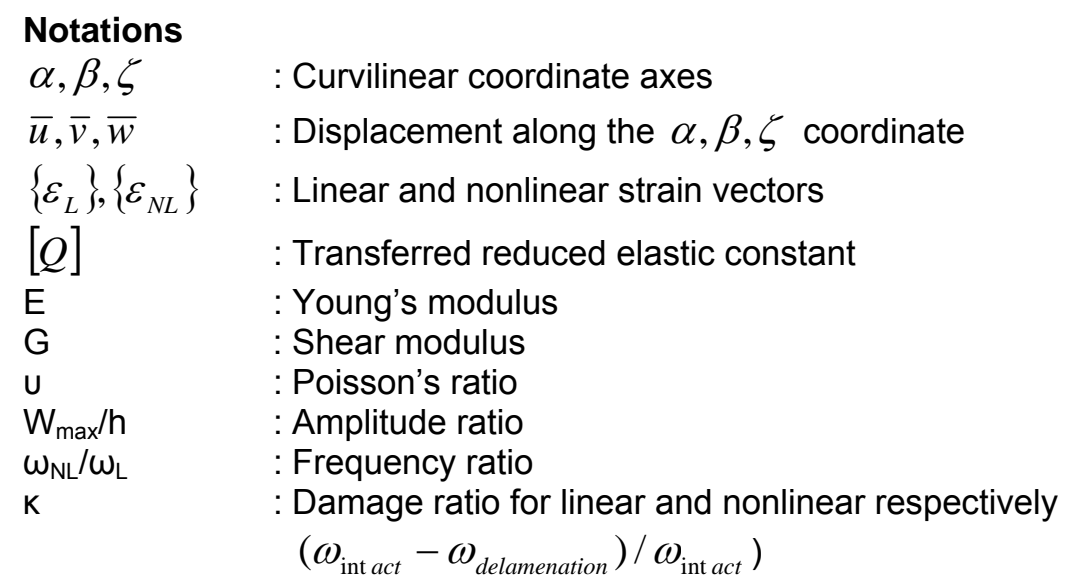

\section{INTRODUCTION}

It is known that delamination are the most frequent causes of failure in laminated structures, particularly under compressive loads. The delaminations in composite materials may occur as a result of various reasons such as manufacturing imperfections, imperfections of various natures, external impacts, thermal and chemical shrinkage of components, and high stress concentrations in the area of geometric or material discontinuities. The presence of delaminations in composite laminates can reduce the overall stiffness and cause the material unbalance in a symmetric laminate. For the past two decades, analytical and numerical analyses have been carried out by many researchers to analyze delaminated composite structures, considering the shear deformation theories. Reddy 1979 using the finite element method to calculate the free vibration of laminated anisotropic plate theory of Yang Norris and Stavsky (this theory is a generalization of Mindlin's theory for isotropic plates to laminated anisotropic plates and includes shear deformation and rotary inertia effects). Shin DK 1997, analyzed the large amplitude vibration of symmetrically laminated moderately thick shallow doubly curved open shells 
with simply supported sides, considering the first order shear deformation theory and nonlinearity in Von-Karman sens. They obtained the governing equations using the Galerkin approximation and solved them by a fourth order Runge Kutta time integration procedure. Reddy and Chao 1981 used the solution of finite element methods to determine the bending deflection, stress, and natural frequency for large deflection theory (Von Karman's), including transverse shear, governing moderately thick, laminated anisotropic composite rectangular plate subjected to various loading and edge condition was presented. The Navier type exact solution are presented by Reddy and Liu 1985 used the high order shear deformation theory of elastic shells is developed for shells laminated of orthotropic layers. The theory is a modification of the Sanders theory and accounts for parabolic distribution of the transverse shear strains through thickness of the shell and tangential stress free boundary conditions on the boundary surfaces of the shell. Shiau and Wu 1991 obtained a high precision based on a simplified high order shear deformation plate theory and using the finite element formulation (72 degree of freedom and triangular element) to determine the natural frequency of laminated plate for deferent type of material and number of layers. The Malekzadeh 2007 studied the effect of different parameters on the convergence and accuracy of natural vibration of the method a differential quadrature for large amplitude free vibration analysis of laminated composite skew plates, the governing equations are based on the thin plate theory (classical linear theory) and geometrical nonlinearity is modeled using Green's strain in conjunction with Von Karman assumption. On the other hand The Ganapathi, et.al, 2009 investigation the free vibration characteristics of simply supported anisotropic composite laminates using analytical approach the formulation is based on the first order shear deformation theory, the governing equation are obtained using energy method. Aditi Chattopadhyay and Haozhong Gu 1995, evaluated the transverse shear effects in delamination buckling of cylindrical shells under axial compression the studying based on the high order shear theory and linear geometry. The Rayleigh Ritz method is used to solve the equations by assuming a double Fourier expansion of the displacements with trigonometric coordinate functions. Hyonny and Keith 1999 are presented an analytical methodology for predicting the buckling initiation of delaminated composite plates it based on the classical plate theory and neglected the effect of shear deformation. Liangjin and Zhengneng 2000 presented a three dimensional model for the analysis of local buckling of stitched composite laminates with an embedded elliptical delamination near the surface, they investigated the effects of stitching, delamination size, delamination orientation and stacking sequence on buckling strains by using the Rayleigh Ritz energy method. Heung and etal 2003 has been developed to investigate and characterize the effect due to presence of discrete single and multiple embedded delaminations on the dynamic response of composite laminated structures with balanced/unbalanced and arbitrary stacking sequences in term of number placement, mode shapes and natural frequencies. Dongwei and Christian 2004 presented an analytical solution to the free vibration of composite beams with two non overlapping delaminations, the Euler Bernoulli beams using the delaminations as their boundaries, the continuity and the equilibrium conditions are satisfied between adjoining beams. Alberto and et.al, 2005 developed the analytical delamination of the strain energy release rates in a delaminated laminate by means of a model of plates which provides no singular stresses, they predict the delamination criteria. Wang and Dong 2005 used the energy method to study hygrothermal effects on local buckling for different delaminated shapes near the surface of cylindrical laminated shells, the effect of non-linear obtained by considering transverse displacements of sub laminate shells and the young's modulus, thermal and humidity expansion coefficients of material are treaded as functions of temperature. Yang and $\mathrm{Fu} 2006$ discussed the effects of delamination sizes, depths, boundary conditions, the material properties and the laminate stacking sequences on delamination growth, based on the variational principle of moving boundary and used classical theory for cylindrical shells. Christian and Dongwei 2007 studied the analytical models and numerical analysis for free vibration of delaminated composites, and they discuss the influence of delamination on the natural frequencies and the mode shapes of composite laminates in addition other factors affecting the vibration of the delaminated composites are discussed. Yang and etal. 2007 discussed the effects of delamination sizes, depths, boundary conditions, the material properties and the laminate stacking sequences on delamination growth, based on the variational principle of moving boundary and considering the contact effect between delamination regions, the first order theory and nonlinear governing equations for the cylindrical shells are derived. Sang and Dae 2007 
studied buckling behaviors of laminated composite structures with a delamination using the enhanced assumed strain (EAS), the EAS three dimensional finite element formulation described and focused on the significant effects of the local buckling for various parameters, such as size of delamination, aspect ratio, width to thickness ratio, stacking sequences and location delamination and multiple delaminations. Züleyha and Mustafa 2008 studied the effect of the size of beneath delaminations has no significant on the critical buckling load and compressive failure load of E-glass/epoxy composite laminates with multiple large delaminations, a numerical and experimental study is carried out to determine the buckling load of rectangular composite plates, for the experiments $\left(0^{\circ} / 90^{\circ} / 0^{\circ} / 90^{\circ}\right)$ s oriented cross-ply laminated plates with multiple large delaminations and without delamination are produced by using hand lay up technique and the results are compare with results obtained by ANSYS 11.0 software and good

$$
\left.\begin{array}{l}
\bar{u}(\alpha, \beta, \zeta, t)=u+\zeta \phi_{1}+\zeta^{2} \psi_{1}+\zeta^{3} \theta_{1} \\
\bar{v}(\alpha, \beta, \zeta, t)=v+\zeta \phi_{2}+\zeta^{2} \psi_{2}+\zeta^{3} \theta_{2} \\
\bar{w}(\alpha, \beta, t)=w
\end{array}\right\}
$$

Where $\mathrm{t}$ is the time, $(\bar{u}, \bar{v}, \bar{w})$ are the displacement along the $(\alpha, \beta, \zeta)$ coordinates, $(u, v, w)$ are the displacements of a point on the mid-plane and $\phi_{1}$ and $\phi_{2}$ are the rotations at $(\zeta=0)$ of normal to the mid-plane respect to the $\alpha$ and $\beta$-axes, respectively, agreement obtained. Alnefaie 2009 developed a three dimensional finite element model of delaminated fiber reinforced composite plates, a classical plate theory is studied during the analyze their dynamics natural frequencies and modal displacements in which are calculated for various case studies with different dimensions and delamination characteristics. A theoretical analysis is investigated in this paper by using finite element method, which is studied the modal analysis of intact and delamination plate.

\section{MATHEMATICAL MODEL}

Displacement field: A shell of length $a$, width $b$ and thickness $\mathrm{h}$ is composed of $\mathrm{N}$ number of orthotropic layers of uniform thickness. The $(\alpha, \beta, \zeta)$ are curvilinear coordinates axes. The following displacement field for the laminated shell based on the HSDT is considered to derive the mathematical model.

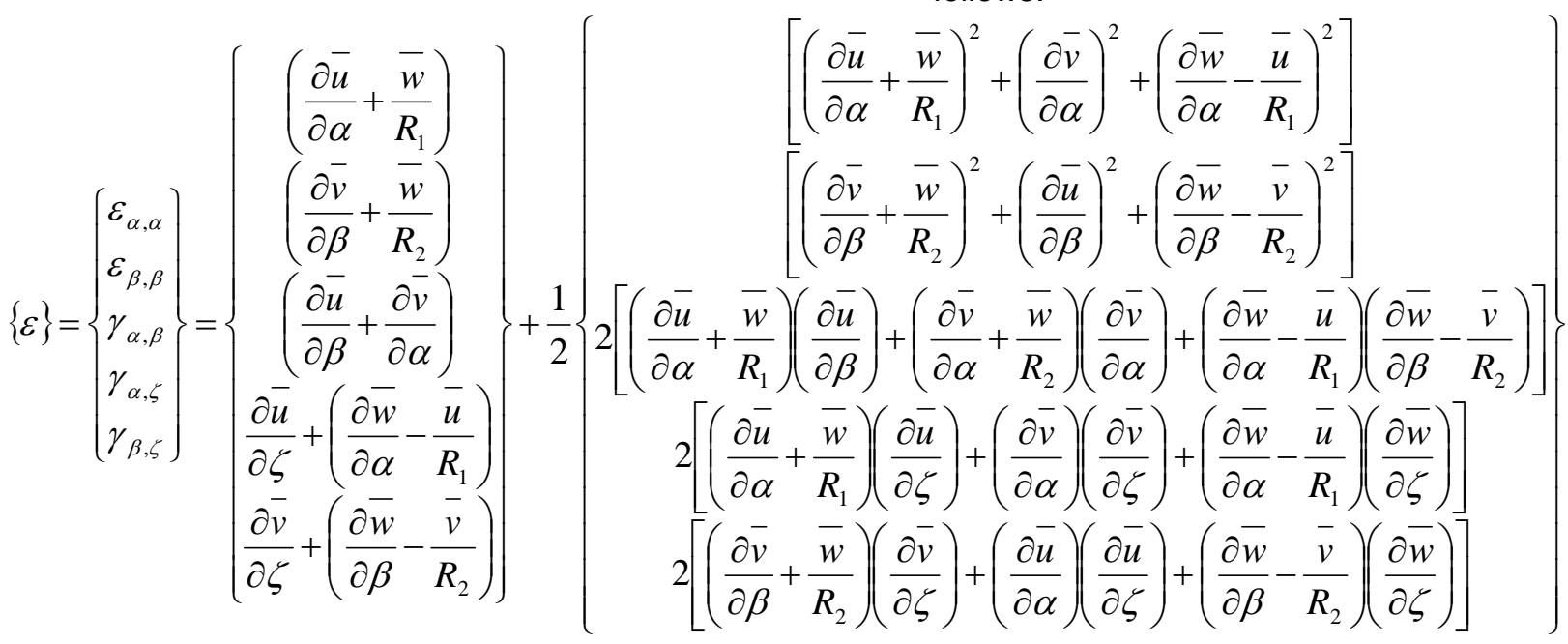

Or, $\{\varepsilon\}=\left\{\varepsilon_{L}\right\}+\left\{\varepsilon_{N L}\right\}$

$\psi_{1}, \psi_{2}, \theta_{1}, \theta_{2}$ are high order terms of Toyler series expansion defined at the mid-plane.

\section{Strain -displacement relation}

The nonlinear Green Lagrange stain displacement relation for the laminated shell can be expressed as follows. 
Where $\left\{\varepsilon_{L}\right\}$ and $\left\{\varepsilon_{N L}\right\}$ are the linear and nonlinear strain vectors respectively. Substituting equation (1) in equation (2), the strain - displacement relation of the laminated shell is expressed as :

$$
\begin{aligned}
& \left\{\varepsilon_{L}\right\}+\left\{\varepsilon_{N L}\right\}=\left\{\begin{array}{c}
\varepsilon_{1}^{0} \\
\varepsilon_{2}^{0} \\
\varepsilon_{6}^{0} \\
\varepsilon_{5}^{0} \\
\varepsilon_{4}^{0}
\end{array}\right\}+\frac{1}{2}\left\{\begin{array}{c}
\varepsilon_{1}^{4} \\
\varepsilon_{2}^{4} \\
2 \varepsilon_{6}^{4} \\
2 \varepsilon_{5}^{4} \\
2 \varepsilon_{4}^{4}
\end{array}\right\}+\zeta\left[\left\{\begin{array}{c}
\chi_{1}^{1} \\
\chi_{2}^{1} \\
\chi_{6}^{1} \\
\chi_{5}^{1} \\
\chi_{4}^{1}
\end{array}\right\}+\frac{1}{2}\left\{\begin{array}{c}
\chi_{1}^{5} \\
\chi_{2}^{5} \\
2 \chi_{6}^{5} \\
2 \chi_{5}^{5} \\
2 \chi_{4}^{5}
\end{array}\right\}+\zeta^{2}\left[\left\{\begin{array}{c}
\chi_{1}^{2} \\
\chi_{2}^{2} \\
\chi_{6}^{2} \\
\chi_{5}^{2} \\
\chi_{4}^{2}
\end{array}\right\}+\frac{1}{2}\left\{\begin{array}{c}
\chi_{1}^{6} \\
\chi_{2}^{6} \\
2 \chi_{6}^{6} \\
2 \chi_{5}^{6} \\
2 \chi_{4}^{6}
\end{array}\right\}\right]\right. \\
& +\zeta^{3}\left[\left\{\begin{array}{l}
\chi_{1}^{3} \\
\chi_{2}^{3} \\
\chi_{6}^{3} \\
\chi_{5}^{3} \\
\chi_{4}^{3}
\end{array}\right\}+\frac{1}{2}\left\{\begin{array}{c}
\chi_{1}^{7} \\
\chi_{2}^{7} \\
2 \chi_{6}^{7} \\
2 \chi_{5}^{7} \\
2 \chi_{4}^{7}
\end{array}\right\}\right]+\zeta^{4}\left[\frac{1}{2}\left\{\begin{array}{c}
\chi_{1}^{8} \\
\chi_{2}^{8} \\
2 \chi_{6}^{8} \\
2 \chi_{5}^{8} \\
2 \chi_{4}^{8}
\end{array}\right\}\right]+\zeta^{5}\left[\frac{1}{2}\left\{\begin{array}{c}
\chi_{1}^{9} \\
\chi_{2}^{9} \\
2 \chi_{6}^{9} \\
2 \chi_{5}^{9} \\
2 \chi_{4}^{9}
\end{array}\right\}\right]+\zeta^{6}\left[\frac{1}{2}\left\{\begin{array}{c}
\chi_{1}^{10} \\
\chi_{2}^{10} \\
2 \chi_{6}^{10} \\
0 \\
0
\end{array}\right\}\right]
\end{aligned}
$$

The value of individual terms of above equation which are provided in Appendix (A). Hence the above equation can be rearrangement such as :

$$
\{\varepsilon\}=\left\{\varepsilon_{L}\right\}+\left\{\varepsilon_{N L}\right\}=[\mathfrak{I}]_{L}\{\varepsilon\}_{L}+\frac{1}{2}[\mathfrak{I}]_{N L}\{\tilde{\varepsilon}\}_{N L}
$$

Where

$$
\begin{aligned}
\{\bar{\varepsilon}\}_{L}= & \left\{\begin{array}{lllllllllllllllllll}
\varepsilon_{1}^{0} & \varepsilon_{2}^{0} & \varepsilon_{6}^{0} & \varepsilon_{5}^{0} & \varepsilon_{4}^{0} & \chi_{1}^{1} & \chi_{2}^{1} & \chi_{6}^{1} & \chi_{5}^{1} & \chi_{4}^{1} & \chi_{1}^{2} & \chi_{2}^{2} & \chi_{6}^{2} & \chi_{5}^{2} & \chi_{4}^{2} \\
& \chi_{1}^{3} & \chi_{2}^{3} & \chi_{6}^{3} & \chi_{5}^{3} & \chi_{4}^{3}
\end{array}\right\} \\
\{\bar{\varepsilon}\}_{N L}= & \left\{\begin{array}{lllllllllllllllll}
\varepsilon_{1}^{4} & \varepsilon_{2}^{4} & \varepsilon_{6}^{4} & \varepsilon_{5}^{4} & \varepsilon_{4}^{4} & \chi_{1}^{5} & \chi_{2}^{5} & \chi_{6}^{5} & \chi_{5}^{5} & \chi_{4}^{5} & \chi_{1}^{6} & \chi_{2}^{6} & \chi_{6}^{6} & \chi_{5}^{6} & \chi_{4}^{6} \\
& \chi_{1}^{7} & \chi_{2}^{7} & \chi_{6}^{7} & \chi_{5}^{7} & \chi_{4}^{7} & \chi_{1}^{8} & \chi_{2}^{8} & \chi_{6}^{8} & \chi_{5}^{8} & \chi_{4}^{8} & \chi_{1}^{9} & \chi_{2}^{9} & \chi_{6}^{9} & \chi_{5}^{9} & \chi_{4}^{9} \\
& \chi_{1}^{10} & \chi_{2}^{10} & \chi_{6}^{10}
\end{array}\right\}
\end{aligned}
$$

\section{Stress - strain relations}

In the analysis of composite laminated materials, the assumption of plane stress is usually used for each layer. This mainly because fiber reinforced material are utilized in beam, plate, cylinders, spherical and other structural shapes which have at least one characteristic geometric dimension in an order of magnitude less than the other two dimensions. In this case the stress components $\left(\sigma_{3}, \tau_{23}, \tau_{13}\right)$ are set to zero. Then The strain displacement relations, for any general $k^{\text {th }}$ orthotropic composite lamina with an arbitrary fiber orientation angle with reference to the coordinate axes $(\alpha, \beta, \zeta)$ is 
Where :

$\bar{Q}_{11}=Q_{11} \cdot \cos ^{4} \vartheta+2\left(Q_{12}+2 Q_{66}\right) \cdot \sin ^{2} \vartheta \cdot \cos ^{2} \vartheta+Q_{22} \cdot \sin ^{4} \vartheta$

$\bar{Q}_{12}=\left(Q_{11}+Q_{22}-4 Q_{66}\right) \cdot \sin ^{2} \vartheta \cdot \cos ^{2} \vartheta+Q_{11}\left(\cos ^{4} \theta+\sin ^{4} \vartheta\right)$

$\bar{Q}_{22}=Q_{11} \sin ^{4} \vartheta+2\left(Q_{12}+2 Q_{66}\right) \sin ^{2} \vartheta \cdot \cos ^{2} \vartheta+Q_{22} \cos ^{4} \vartheta$

$\bar{Q}_{16}=\left(Q_{11}-Q_{12}-2 Q_{66}\right) \sin \vartheta \cdot \cos ^{3} \vartheta+\left(Q_{12}-Q_{22}+2 Q_{66}\right) \sin ^{3} \vartheta \cdot \cos \vartheta$

$\bar{Q}_{26}=\left(Q_{11}-Q_{12}-2 Q_{66}\right) \sin ^{3} \vartheta \cdot \cos \vartheta+\left(Q_{12}-Q_{22}+2 Q_{66}\right) \sin \vartheta \cdot \cos ^{3} \vartheta$

$\bar{Q}_{66}=\left(Q_{11}+Q_{22}-2 Q_{12}-2 Q_{66}\right) \sin ^{2} \vartheta \cdot \cos ^{2} \vartheta+Q_{66}\left(\sin ^{4} \vartheta+\cos ^{4} \vartheta\right)$

$\bar{Q}_{44}=Q_{44} \cos ^{2} \vartheta+Q_{55} \sin ^{2} \vartheta$

$\bar{Q}_{45}=\left(Q_{55}-Q_{44}\right) \cos \vartheta \cdot \sin \vartheta$

$\bar{Q}_{55}=Q_{55} \cos _{2} \vartheta+Q_{44} \sin _{2} \vartheta$

\section{Strain energy of the laminate}

Energy and variational principle offered great simplification to many derivations of fundamental equations in elasticity. Also have been used to introduce and implement approximation techniques

$U=\frac{1}{2} \int_{V}\{\varepsilon\}_{i}^{T} \cdot\left\{\sigma_{i}\right\} d V$

By substituting the strains from equation (2) and stresses from equation (5) into equation (6), the strain energy can be expressed as :

$$
\begin{aligned}
U & =\frac{1}{2} \int_{V}\left\{\varepsilon_{L}+\varepsilon_{N L}\right\}_{i}^{T}[\bar{Q}]\left\{\varepsilon_{L}+\varepsilon_{N L}\right\}_{i} d V \\
& =\frac{1}{2} \int\left(\left\{\varepsilon_{L}\right\}_{i}^{T}\left[D_{1}\right]\left\{\varepsilon_{L}\right\}_{i}+\frac{1}{2}\left\{\varepsilon_{L}\right\}_{i}^{T}\left[D_{2}\right]\left\{\varepsilon_{N L}\right\}_{i}+\frac{1}{2}\left\{\varepsilon_{N L}\right\}_{i}^{T}\left[D_{3}\right]\left\{\varepsilon_{L}\right\}_{i}+\frac{1}{4}\left\{\varepsilon_{N L}\right\}_{i}^{T}\left[D_{4}\right]\left\{\varepsilon_{N L}\right\}_{i}\right) d A
\end{aligned}
$$

Where :

$$
\begin{aligned}
& \left.\left[D_{1}\right]=\sum_{k=1}^{N} \int_{\zeta_{k-1}}^{\zeta_{k}}[\mathfrak{I}]_{L}^{T}[\bar{Q}] \mathfrak{I}\right]_{L} d \zeta \\
& {\left[D_{2}\right]=\sum_{k=1}^{N} \int_{\zeta_{k-1}}^{\zeta_{k}}[\mathfrak{I}]_{L}^{T}[\bar{Q}][\mathfrak{I}]_{N L} d \zeta} \\
& \left.\left[D_{3}\right]=\sum_{k=1}^{N} \int_{\zeta_{k-1}}^{\zeta_{k}}[\mathfrak{I}]_{N L}^{T}[\bar{Q}] \mathfrak{I}\right]_{L} d \zeta \\
& \left.\left[D_{4}\right]=\sum_{k=1}^{N} \int_{\zeta_{k-1}}^{\zeta_{k}}[\mathfrak{I}]_{N L}^{T}[\bar{Q}] \mathfrak{I}\right]_{N L} d \zeta
\end{aligned}
$$

for structural systems. Strain energy is defined as the work done by the internal stresses which caused elongation or shear strains. The strain energy of the plate can be expressed as :

\footnotetext{
Where : $\mathrm{N}$ is the numbers of layers
} 
Kinetic energy of the vibrating plate: The kinetic energy expression of a vibrated shell can be expressed as $T=\frac{1}{2} \int_{V} \rho\{\overline{\dot{\delta}}\}^{T}\{\overline{\dot{\delta}}\} d V$

Where, $\rho$ and $\overline{\dot{\delta}}$ are the density and displacement vector which differentia the first order of displacement

with respect to time, respectively. The global displacement vector can be expressed as :

$\{\overline{\dot{\delta}}\}_{i}=\left\{\begin{array}{c}\overline{\dot{u}} \\ \overline{\dot{v}} \\ \overline{\dot{w}}\end{array}\right\}=\left[\begin{array}{ccccccccc}1 & 0 & 0 & \zeta & 0 & \zeta^{2} & 0 & \zeta^{3} & 0 \\ 0 & 1 & 0 & 0 & \zeta & 0 & \zeta^{2} & 0 & \zeta^{3} \\ 0 & 0 & 1 & 0 & 0 & 0 & 0 & 0 & 0\end{array}\right]\left\{\begin{array}{c}\dot{u} \\ \dot{v} \\ \dot{w} \\ \dot{\phi}_{1} \\ \dot{\phi}_{2} \\ \dot{\psi}_{1} \\ \dot{\psi}_{2} \\ \dot{\theta}_{1} \\ \dot{\theta}_{2}\end{array}\right\}=[f]\{\dot{\delta}\}$

Where, $[f]$ is the function of the thickness coordinate.

layered composite plate obtained by substituting the Then the kinetic energy for ' $N$ ' number of orthotropic equation (9) into equation (8) obtain.

$$
\begin{aligned}
& T=\frac{1}{2} \int_{A}\left(\sum_{k=1}^{N} \int_{\zeta_{k-1}}^{\zeta_{k}}\{\dot{\delta}\}^{T}[f]^{T} \rho^{k}[f]\{\dot{\delta}\} \mathrm{d} \zeta\right) \mathrm{dA} \\
& T=\frac{1}{2} \int_{\mathrm{A}}\{\dot{\delta}\}^{T}[m]\{\dot{\delta}\} \mathrm{dA}
\end{aligned}
$$

Where, $[m]=\sum_{k=1}^{N} \int_{\zeta_{\mathrm{k}-1}}^{\zeta_{\mathrm{k}}}\left([f]^{T} \rho^{k}[f]\right) \mathrm{d} \zeta$ is the inertia matrix.

\section{Solution Technique}

The displacement vector can be conceded to the form by employing the FEM $\{\delta\}=\left[N_{i}\right]\left\{\delta_{i}\right\}$

Where :

$$
\left\{\delta_{i}\right\}=\left[\begin{array}{lllllllll}
u_{i} & v_{i} & w_{i} & \phi_{1} & \phi_{2} & \psi_{1} & \psi_{2} & \theta_{1} & \theta_{2}
\end{array}\right]^{T}
$$

The equations of strain for linear and nonlinear are studied of large deflections, as in equation (4) and substituted into equation (7), the strain energy can be written as

$$
\text { nonlinear displacement in equation (1), when }
$$

$$
\begin{gathered}
U=\frac{1}{2} \int_{A}\left(\left[B_{L}\right]_{i}^{T}\{\delta\}_{i}^{T}\left[D_{1}\right]\left[B_{L}\right]_{i}\{\delta\}_{i}+\frac{1}{2}\left[B_{L}\right]_{i}^{T}\{\delta\}_{i}^{T}\left[D_{2}\right]\left[B_{N L}\right]_{i}\{\delta\}_{i}+\frac{1}{2}\left[B_{N L}\right]_{i}^{T}\{\delta\}_{i}^{T}\left[D_{3}\right]\left[B_{L}\right]_{i}\{\delta\}_{i}\right. \\
\left.\frac{1}{4}\left[B_{N L}\right]_{i}^{T}\{\delta\}_{i}^{T}\left[D_{4}\right]\left[B_{N L}\right]\{\delta\}_{i}^{T}\right) d A
\end{gathered}
$$


Where $\left[B_{N L}\right]_{i}=[A]_{i}[G]_{i},[A]_{33 \times 27}$ is function to the displacements and $[G]_{27 \times 9}$ is the product form of differential operator and shape function in the nonlinear strain terms. $\left[\mathrm{B}_{\mathrm{L}}\right]_{20 \times 9}$ is the product form of the differential operator and nodal interpolation function in the linear terms. The value of individual terms of $\left[B_{L}\right]$ and $\left[B_{N L}\right]$ which are provided in Appendix (B)

The final form of governing equation for the nonlinear free vibration laminated plate panel is obtained by using Hamilton's principle. It can be viewed and axiom, from which other axioms like Newton's second law, Define the potential energy to be $(\Pi=U-W)$, which $U$ is the strain energy and $W$ is the work done and the Lagrangian as the function $L$ where $(L=(T-$ $U+W)$ ).

Hamilton's principle states that the actual displacement that the body actually goes through from instant $\left(t_{1}\right)$ to instant $\left(t_{2}\right)$ out of many possible paths, is that which achieves an extremum of the line integral of the Lagrangian function. This is achieved if the variation of the time integral of the Lagrangian is set to zero:

$$
\delta \int_{t_{1}}^{t_{2}} L d t=0
$$

Hamilton's principle can be used to find the compatible set of equations of motion and boundary conditions for given stresses and strains. This is done by substituting the equations for strain energy equation (12) and kinetic energy equation (10) into the equation (13), performing the integration by parts, and setting the coefficients of the displacement variations (also called virtual displacement) equal to zero. The Lagrangian becomes (Marco, 2008).

$$
[M]\{\ddot{\delta}\}+\left(\left[K_{L}\right]+\left[K_{L}\right]\right)\{\delta\}=0
$$

Where $\{\delta\}$ is the displacement vector, $[M],\left[K_{L}\right]$ and $\left[K_{N L}\right]$ are the global mass matrix and global linear stiffness matrix and nonlinear stiffness matrix that depend on the displacement vector respectively.

\section{Damage modeling}

Defect and damages are caused the laminates to lose their strength and rigidity and also the safe working life is reduced. Defects and damages can creep in at any time like manufacturing, in service or in design due to discontinuities such as cut out and play drops. The investigation of defects and damages are presented. By using the following expansion of the displacements through the thickness of the shell.

$$
\left.\begin{array}{l}
\bar{u}(\alpha, \beta, \zeta, t)=u+\zeta \phi_{1}+\zeta^{2} \psi_{1}+\zeta^{3} \theta_{1}+\sum_{1}^{N D} H^{\prime}(z) U^{\prime}(\alpha, \beta) \\
\bar{v}(\alpha, \beta, \zeta, t)=v+\zeta \phi_{2}+\zeta^{2} \psi_{2}+\zeta^{3} \theta_{2}+\sum_{1}^{N D} H^{\prime}(z) V^{\prime}(\alpha, \beta) \\
\bar{w}(\alpha, \beta, t)=w+\sum_{1}^{N D} H^{\prime}(z) W^{\prime}(\alpha, \beta)
\end{array}\right\}
$$

Where the step functions $H^{\prime}$ are computed in terms of Heaviside functions $H^{\prime}$ as :

$$
\begin{array}{ll}
H^{\prime}(z)=H^{\prime}\left(z-z_{j}\right)=1 & \text { for } \quad z \geq z_{j} \\
H^{\prime}(z)=H^{\prime}\left(z-z_{j}\right)=0 & \text { for } \quad z\left\langle z_{j}\right.
\end{array}
$$

And the ND is the number of delaminations. The jumps in the displacements at the $j^{\text {th }}$ delaminated interface are given by $U^{\prime}, V^{\prime}$ and $W^{\prime}$. Using the step functions $H^{\prime}(z)$, it can be model any number of delaminations through thickness; the number of additional variable is equal to the number of delaminations considered(Barbero and Reddy, 1991).

Then substituting equation (16) into the nonlinear Green Lagrange stain displacement relation for the laminated shell, equation (2) will be: 


$$
\begin{aligned}
& \left\{\varepsilon_{L}\right\}+\left\{\varepsilon_{N L}\right\}=\left\{\begin{array}{l}
\varepsilon_{1}^{0} \\
\varepsilon_{2}^{0} \\
\varepsilon_{6}^{0} \\
\varepsilon_{5}^{0} \\
\varepsilon_{4}^{0}
\end{array}\right\}+\left\{\begin{array}{l}
\varepsilon_{d 1}^{0} \\
\varepsilon_{d 2}^{0} \\
\varepsilon_{d 6}^{0} \\
\varepsilon_{d 5}^{0} \\
\varepsilon_{d 4}^{0}
\end{array}\right\}+\frac{1}{2}\left\{\begin{array}{c}
\varepsilon_{1}^{4} \\
\varepsilon_{2}^{4} \\
2 \varepsilon_{6}^{4} \\
2 \varepsilon_{5}^{4} \\
2 \varepsilon_{4}^{4}
\end{array}\right\}+\frac{1}{2}\left\{\begin{array}{c}
\varepsilon_{d 1}^{4} \\
\varepsilon_{d 2}^{4} \\
2 \varepsilon_{d 6}^{4} \\
2 \varepsilon_{d 5}^{4} \\
2 \varepsilon_{d 4}^{4}
\end{array}\right\}+\zeta\left[\left\{\left[\begin{array}{c}
\chi_{1}^{1} \\
\chi_{2}^{1} \\
\chi_{6}^{1} \\
\chi_{5}^{1} \\
\chi_{4}^{1}
\end{array}\right\}+\frac{1}{2}\left\{\begin{array}{c}
\chi_{1}^{5} \\
\chi_{2}^{5} \\
2 \chi_{6}^{5} \\
2 \chi_{5}^{5} \\
2 \chi_{4}^{5}
\end{array}\right\}+\frac{1}{2}\left\{\begin{array}{c}
\chi_{d 1}^{5} \\
\chi_{d 2}^{5} \\
2 \chi_{d 6}^{5} \\
2 \chi_{d 5}^{5} \\
2 \chi_{d 4}^{5}
\end{array}\right\}\right]\right. \\
& \left.+\zeta^{2}\left[\left\{\begin{array}{c}
\chi_{1}^{2} \\
\chi_{2}^{2} \\
\chi_{6}^{2} \\
\chi_{5}^{2} \\
\chi_{4}^{2}
\end{array}\right\}+\frac{1}{2}\left\{\begin{array}{c}
\chi_{1}^{6} \\
\chi_{2}^{6} \\
2 \chi_{6}^{6} \\
2 \chi_{5}^{6} \\
2 \chi_{4}^{6}
\end{array}\right\} \frac{1}{2}\left\{\begin{array}{c}
\chi_{d 1}^{6} \\
\chi_{d 2}^{6} \\
2 \chi_{d 6}^{6} \\
2 \chi_{d 5}^{6} \\
2 \chi_{d 4}^{6}
\end{array}\right\}\right]+\zeta^{3}\left[\begin{array}{c}
\chi_{1}^{3} \\
\chi_{2}^{3} \\
\chi_{6}^{3} \\
\chi_{5}^{3} \\
\chi_{4}^{3}
\end{array}\right\}+\frac{1}{2}\left\{\begin{array}{c}
\chi_{1}^{7} \\
\chi_{2}^{7} \\
2 \chi_{6}^{7} \\
2 \chi_{5}^{7} \\
2 \chi_{4}^{7}
\end{array}\right\}+\frac{1}{2}\left\{\begin{array}{c}
\chi_{d 1}^{7} \\
\chi_{d 2}^{7} \\
2 \chi_{d 6}^{7} \\
0 \\
0
\end{array}\right\}\right] \\
& +\zeta^{4}\left[\frac{1}{2}\left\{\begin{array}{c}
\chi_{1}^{8} \\
\chi_{2}^{8} \\
2 \chi_{6}^{8} \\
2 \chi_{5}^{8} \\
2 \chi_{4}^{8}
\end{array}\right\}\right]+\zeta^{5}\left[\frac{1}{2}\left\{\begin{array}{c}
\chi_{1}^{9} \\
\chi_{2}^{9} \\
2 \chi_{6}^{9} \\
2 \chi_{5}^{9} \\
2 \chi_{4}^{9}
\end{array}\right\}\right]+\zeta^{6}\left[\frac{1}{2}\left\{\begin{array}{c}
\chi_{1}^{10} \\
\chi_{2}^{10} \\
2 \chi_{6}^{10} \\
0 \\
0
\end{array}\right\}\right]
\end{aligned}
$$

Where the parameter of equation (17) can be show in Appendix (A). The generalized displacements (DOF) in this case are $\left(u, v, w, \phi_{1}, \phi_{2}, \psi_{1}, \psi_{2}, \theta_{1}, \theta_{2}, U^{\prime}, V^{\prime}, W^{\prime}\right)$. The effect of delamination on the stiffness is much higher compared to the mass, hence it can be considered the same mass matrix in equation (10).

\section{NUMERICAL RESULTS AND DISCUSSION}

A nonlinear finite element code using the present displacement field shell model in Green-Lagrange sense in the framework of the HSDT. The validation and accuracy of the present algorithm are examined by comparing the results with those available in the literature. The effect of different combinations of the material orthotropy, amplitude ratio $\left(\mathrm{W}_{\max } / \mathrm{h}\right)$, where $\mathrm{W}_{\max }$ is the maximum deflection of shell and $\mathrm{h}$ is the thickness, and different size of delamination are also study.

The following sets of boundary conditions are used for the present analysis'

a) Simply support boundary conditions (S):

$$
\begin{aligned}
v=w=\phi_{2}=\psi_{2}= & \theta_{2}=0 \\
& \text { at } \mathrm{x}=0, \mathrm{a} \\
u=w=\phi_{1}=\psi_{1}= & \theta_{1}=0 \\
& \text { at } \mathrm{y}=0, \mathrm{~b}
\end{aligned}
$$


A convergence of the mathematical model developed for laminated shell is presented Figures (1) and (2) are shown the nondimensional fundamental frequency $\left(\varpi=\omega n_{L}\left(\frac{a^{2}}{h}\right) \sqrt{\left(\frac{\rho}{E_{2}}\right)}\right)$, and frequency ratio $\left(\omega_{N L} / \omega_{L}\right)$ against mesh division respectively for simply support boundary condition and for different stacking sequences, The results are plotted using the material properties $\left(E_{1}=181 \mathrm{GPa}, E_{2}=7.17 \mathrm{GPa}\right.$, $G_{23}=6.71 \mathrm{GPa}, \quad U_{12}=0.28$, and the geometry parameters are $a / b=1, a / h=10$ ). From these figures it can be shown that the convergence is a (5X5) mesh, then it's used to compute the results throughout the study.

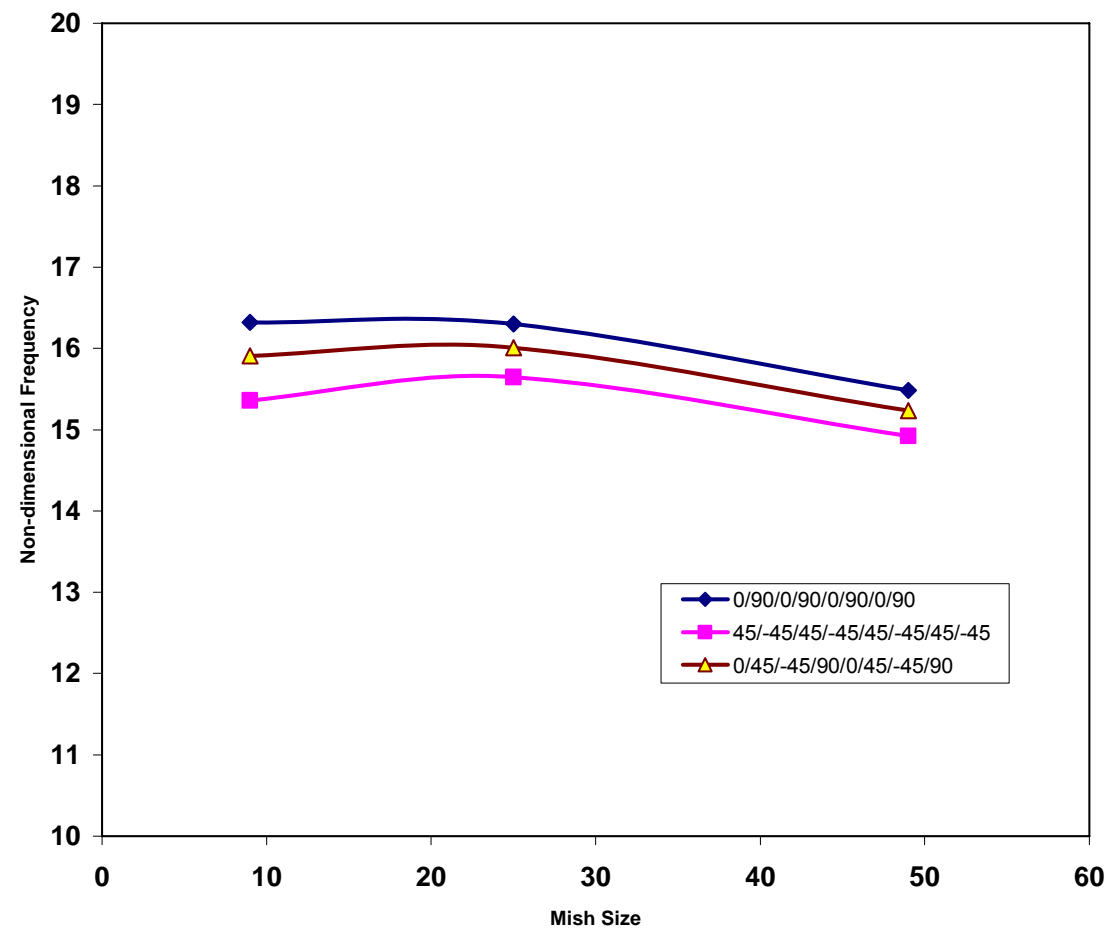

Fig 1. Convergence study of non-dimensional frequency for square shell having SSSS boundary condition with different stacking sequences

In order to show the validation of the present intact model, simply supported square laminated cylindrical shell panels of symmetric angle ply lamination $\left[ \pm 45^{\circ}\right]_{\mathrm{s}}$ are studied with the geometry cylindrical shell $(a / b=1$, $a / h=10$ and $R_{1} / h=100$ ). The composite properties $\left(E_{1}=181 \mathrm{GPa}, \quad E_{2}=10.3 \mathrm{GPa}, \mathrm{G}_{12}=7.17 \mathrm{GPa}\right.$, $G_{23}=6.21 \mathrm{GPa}$ and $v_{12}=0.28$ ) are used for the computation of the result. The results in terms of the frequency ratio $\left(\frac{\sigma_{N L}}{\sigma_{L}}\right)$, i.e., ratio of the nonlinear frequency to linear frequency are computed for different amplitude ratios $\left(W_{\max } / h\right)$. The present results and their differences with the existing result (Shin DK. 1997) are depicted in Table (1). The differences are more pronounced because the present study deals with all the higher order terms of Green-Lagrange strains in the framework of the high shear order theory. Due to this, the stiffness matrix becomes more flexure and approaches towards the more general case, i.e., Green-Lagrange. However, the published results (Shin DK. 1997) have been obtained using the Von-Karman strains in the framework of the first shear order theory.

The effect of material orthotropy on the frequency ratio of the nonlinear free vibration of square laminated cylindrical shell for intact and delamination cases are studied for four different modular ratio $\left(E_{1} / E_{2}=3,5,10\right.$ and 15$)$ with other parameters such as $\mathrm{G}_{12} / \mathrm{E}_{2}=0.6, \mathrm{G}_{23} / \mathrm{E}_{2}=0.5, \mathrm{v} 12=0.25, \mathrm{a} / \mathrm{b}=1, \mathrm{a} / \mathrm{h}=10$, $\mathrm{R} / \mathrm{a}=5$ ) for all sides simply supported boundary 
condition (SSSS). The results of the linear fundamental frequency increase with increasing in modular ratio and decreasing in natural frequency in the delamination case as shown in figure (2). The frequency ratio decreases with increase in modular ratio and diverged in some results because in the present work, the framework of the high order shear theory and geometrical nonlinearity modeled with Green's strain is used as shown in Table (2).

Table 1. Comparison of frequency ratio $\left(\frac{\sigma_{N L}}{\sigma_{L}}\right)$ of square angle $\left[ \pm 45^{\circ}\right]_{\mathbf{s}}$ laminated cylindrical shell for SSSS boundary condition

\begin{tabular}{|c|c|c|c|}
\hline$W_{\max } / h$ & Shin DK. 1997 & Present Work & error (\%) \\
\hline 0.2 & 1.0281 & 1.166719135 & 11.88110578 \\
\hline 0.4 & 1.0957 & 1.019832623 & 7.439198871 \\
\hline 0.6 & 1.2023 & 0.936271035 & 28.41367032 \\
\hline 0.8 & 1.30368 & 0.99989171 & 30.38211909 \\
\hline \multicolumn{3}{|c|}{ average error } \\
\hline
\end{tabular}

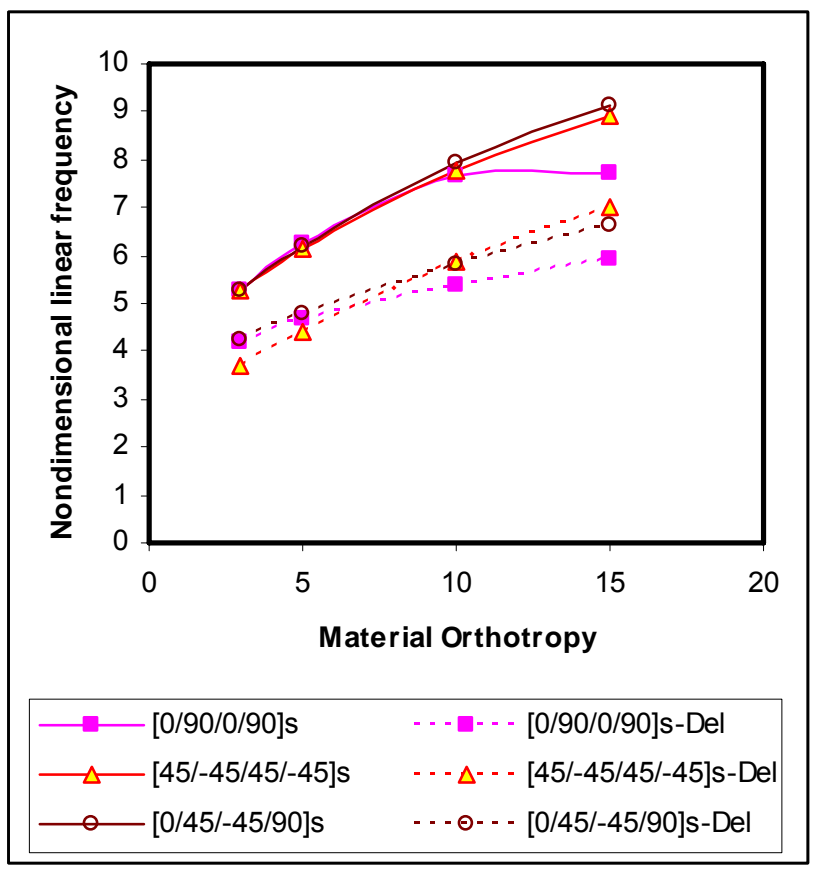

Fig 2. The linear fundamental frequency and material orthotropy for difference stacking sequence 
Am. J. Sci. Ind. Res., 2011, 2(2): 251-277

Table 2. The frequency ratio with different material orthotropy

\begin{tabular}{|c|c|c|c|c|c|c|c|c|}
\hline \multicolumn{9}{|c|}{ 0/90/0/90/0/90/0/90 } \\
\hline Wmax/ly & Intact & $\begin{array}{l}\text { Delamin } \\
\text { ation }\end{array}$ & Intact & $\begin{array}{c}\text { Delamin } \\
\text { ation }\end{array}$ & Intact & $\begin{array}{l}\text { Delamin } \\
\text { ation }\end{array}$ & Intact & $\begin{array}{c}\text { Delamin } \\
\text { ation }\end{array}$ \\
\hline E1/E2 & 3 & 3 & 5 & 5 & 10 & 10 & 15 & 15 \\
\hline 0.5 & $\begin{array}{r}1.675601 \\
775\end{array}$ & $\begin{array}{r}1.483314 \\
49\end{array}$ & $\begin{array}{r}1.427827 \\
522\end{array}$ & $\begin{array}{r}1.333849 \\
59\end{array}$ & $\begin{array}{r}1.175672 \\
797\end{array}$ & $\begin{array}{r}1.002505 \\
573\end{array}$ & $\begin{array}{r}1.117122 \\
228\end{array}$ & $\begin{array}{r}1.003080 \\
242\end{array}$ \\
\hline 1 & $\begin{array}{r}1.550247 \\
521\end{array}$ & $\begin{array}{r}1.370376 \\
518\end{array}$ & $\begin{array}{r}1.301952 \\
107\end{array}$ & $\begin{array}{r}1.230911 \\
296\end{array}$ & $\begin{array}{r}1.062937 \\
543\end{array}$ & $\begin{array}{r}1.000003 \\
557\end{array}$ & $\begin{array}{r}1.117122 \\
228\end{array}$ & $\begin{array}{r}0.999999 \\
83\end{array}$ \\
\hline 1.5 & $\begin{array}{r}1.513938 \\
281\end{array}$ & $\begin{array}{r}1.312351 \\
103\end{array}$ & $\begin{array}{r}1.272512 \\
994\end{array}$ & $\begin{array}{r}1.099237 \\
74\end{array}$ & $\begin{array}{r}1.040317 \\
693\end{array}$ & $\begin{array}{r}1.000001 \\
059\end{array}$ & $\begin{array}{r}1.029696 \\
605\end{array}$ & $\begin{array}{r}0.999999 \\
871\end{array}$ \\
\hline 2 & $\begin{array}{r}1.501014 \\
128 \\
\end{array}$ & $\begin{array}{r}1.029049 \\
62 \\
\end{array}$ & $\begin{array}{r}1.262079 \\
403 \\
\end{array}$ & $\begin{array}{r}0.977837 \\
573 \\
\end{array}$ & $\begin{array}{r}1.032320 \\
108 \\
\end{array}$ & $\begin{array}{r}0.990012 \\
135 \\
\end{array}$ & $\begin{array}{r}1.024744 \\
024 \\
\end{array}$ & $\begin{array}{r}1.000016 \\
052 \\
\end{array}$ \\
\hline \multicolumn{9}{|c|}{ 45/-45/45/-45/45/-45/45/-45 } \\
\hline & Intact & $\begin{array}{c}\text { Delamin } \\
\text { ation }\end{array}$ & Intact & $\begin{array}{c}\text { Delamin } \\
\text { ation }\end{array}$ & Intact & $\begin{array}{c}\text { Delamin } \\
\text { ation }\end{array}$ & Intact & $\begin{array}{c}\text { Delamin } \\
\text { ation }\end{array}$ \\
\hline E1/E2 & 3 & 3 & 5 & 5 & 10 & 10 & 15 & 15 \\
\hline 0.5 & $\begin{array}{r}1.672687 \\
558\end{array}$ & $\begin{array}{r}1.771954 \\
696\end{array}$ & $\begin{array}{r}1.452920 \\
104\end{array}$ & $\begin{array}{r}1.818821 \\
057\end{array}$ & $\begin{array}{r}1.099978 \\
72\end{array}$ & $\begin{array}{r}1.744679 \\
145\end{array}$ & $\begin{array}{r}1.017880 \\
288\end{array}$ & $\begin{array}{r}1.002234 \\
394\end{array}$ \\
\hline 1 & $\begin{array}{r}1.553799 \\
051\end{array}$ & $\begin{array}{r}1.366384 \\
294\end{array}$ & $\begin{array}{r}1.326470 \\
525\end{array}$ & $\begin{array}{r}1.697110 \\
773\end{array}$ & $\begin{array}{r}1.033026 \\
536\end{array}$ & $\begin{array}{r}1.547409 \\
724\end{array}$ & $\begin{array}{r}0.914623 \\
179\end{array}$ & $\begin{array}{r}1.000350 \\
891\end{array}$ \\
\hline 1.5 & $\begin{array}{r}1.515533 \\
463\end{array}$ & $\begin{array}{r}1.071038 \\
765\end{array}$ & $\begin{array}{r}1.298163 \\
075\end{array}$ & $\begin{array}{r}1.356139 \\
583\end{array}$ & $\begin{array}{r}1.020317 \\
205\end{array}$ & $\begin{array}{r}0.969178 \\
276\end{array}$ & $\begin{array}{r}0.893767 \\
2\end{array}$ & $\begin{array}{r}0.999860 \\
939\end{array}$ \\
\hline 2 & $\begin{array}{r}1.501928 \\
192 \\
\end{array}$ & $\begin{array}{r}1.020584 \\
201 \\
\end{array}$ & $\begin{array}{r}1.288115 \\
066 \\
\end{array}$ & $\begin{array}{r}1.142451 \\
8 \\
\end{array}$ & $\begin{array}{r}1.015760 \\
335 \\
\end{array}$ & $\begin{array}{r}0.949209 \\
898 \\
\end{array}$ & $\begin{array}{r}0.886401 \\
958 \\
\end{array}$ & $\begin{array}{r}1.000088 \\
037\end{array}$ \\
\hline \multicolumn{9}{|c|}{$0 / 45 /-45 / 90 / 0 / 45 /-45 / 90$} \\
\hline & Intact & $\begin{array}{c}\text { Delamin } \\
\text { ation }\end{array}$ & Intact & $\begin{array}{c}\text { Delamin } \\
\text { ation }\end{array}$ & Intact & $\begin{array}{l}\text { Delamin } \\
\text { ation }\end{array}$ & Intact & $\begin{array}{c}\text { Delamin } \\
\text { ation }\end{array}$ \\
\hline E1/E2 & 3 & 3 & 5 & 5 & 10 & 10 & 15 & 15 \\
\hline 0.5 & $\begin{array}{r}1.801625 \\
814\end{array}$ & $\begin{array}{r}1.581333 \\
282\end{array}$ & $\begin{array}{r}1.390681 \\
066\end{array}$ & $\begin{array}{r}1.359884 \\
505\end{array}$ & $\begin{array}{r}1.083540 \\
855\end{array}$ & $\begin{array}{r}1.230191 \\
371\end{array}$ & $\begin{array}{r}0.949228 \\
308\end{array}$ & $\begin{array}{r}1.184628 \\
365\end{array}$ \\
\hline 1 & $\begin{array}{r}1.595032 \\
813 \\
\end{array}$ & $\begin{array}{r}1.429661 \\
139 \\
\end{array}$ & $\begin{array}{r}1.293940 \\
772 \\
\end{array}$ & $\begin{array}{r}1.253606 \\
461 \\
\end{array}$ & $\begin{array}{r}1.013675 \\
441 \\
\end{array}$ & $\begin{array}{r}1.133661 \\
353 \\
\end{array}$ & $\begin{array}{r}0.881421 \\
544 \\
\end{array}$ & $\begin{array}{r}1.083337 \\
08 \\
\end{array}$ \\
\hline 1.5 & $\begin{array}{r}1.542807 \\
236\end{array}$ & $\begin{array}{r}1.370249 \\
937\end{array}$ & $\begin{array}{r}1.275432 \\
51\end{array}$ & $\begin{array}{r}1.202361 \\
849\end{array}$ & $\begin{array}{r}1.000400 \\
976\end{array}$ & $\begin{array}{r}1.083398 \\
547\end{array}$ & $\begin{array}{r}0.868473 \\
041\end{array}$ & $\begin{array}{r}1.032707 \\
487\end{array}$ \\
\hline 2 & $\begin{array}{r}1.522630 \\
134 \\
\end{array}$ & $\begin{array}{r}1.332219 \\
576 \\
\end{array}$ & $\begin{array}{r}1.268770 \\
403 \\
\end{array}$ & $\begin{array}{r}1.086222 \\
301 \\
\end{array}$ & $\begin{array}{r}0.995659 \\
265 \\
\end{array}$ & $\begin{array}{r}0.962361 \\
94 \\
\end{array}$ & $\begin{array}{r}0.863880 \\
721 \\
\end{array}$ & $\begin{array}{r}1.000004 \\
516 \\
\end{array}$ \\
\hline
\end{tabular}

The effect of delamination on the natural frequency, it is decreasing the natural frequency with increasing the size of defect, because of the increase in the delamination size this lead to increase in reduction in stiffness matrix as shown in the Figure (3). The frequency ratio increases with increasing in delamination size and diverges in some results because the framework of the high order shear theory and geometrical nonlinearity modeled with Green's strain is used in this work as shown in Table (3). 
Am. J. Sci. Ind. Res., 2011, 2(2): 251-277

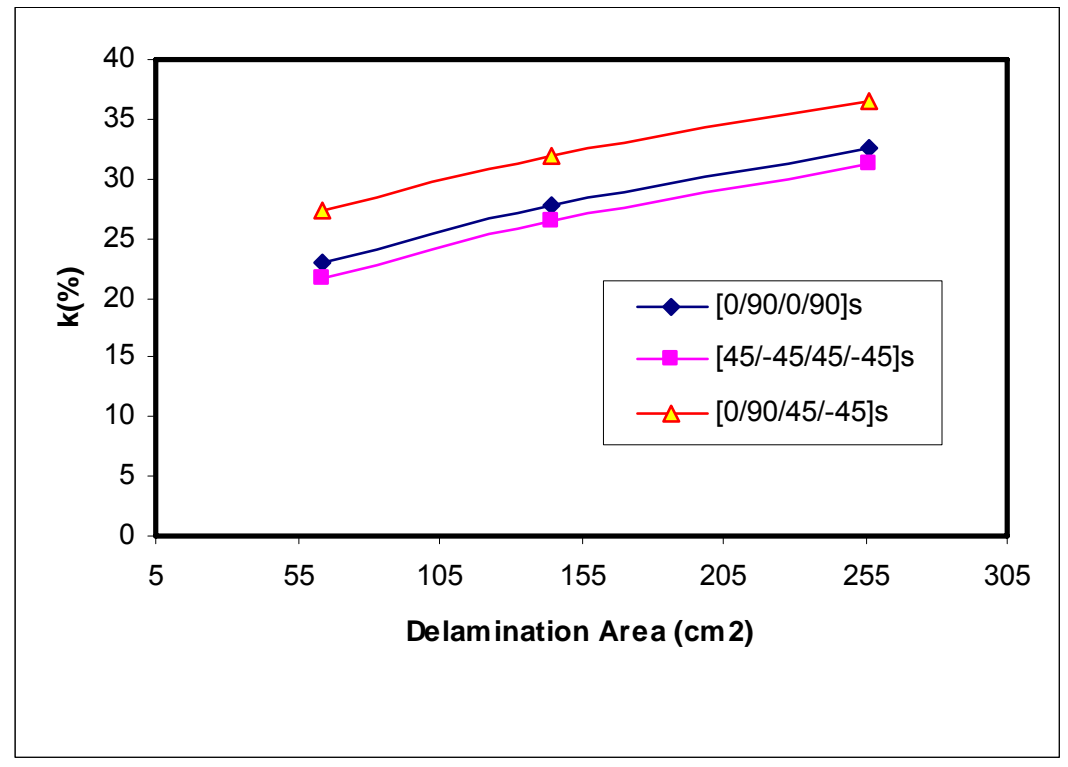

Fig 3. Reduction in natural frequency for intact and delamination via. The size of delamination

Table 3. The frequency ratio with different amplitude ratio for different delamination size

\begin{tabular}{|c|c|c|c|c|}
\hline \multicolumn{5}{|c|}{ 0/90/0/90/0/90/0/90 } \\
\hline \multirow[b]{2}{*}{ Wmax/h } & \multirow[b]{2}{*}{ Intact } & \multicolumn{3}{|c|}{ Delamination Size } \\
\hline & & $8 \times 8 \mathrm{~cm}$ & $12 \times 12 \mathrm{~cm}$ & $16 \times 16 \mathrm{~cm}$ \\
\hline 0.5 & 1.117122228 & 1.003080242 & 1.025918385 & 1.048756527 \\
\hline 1 & 1.117122228 & 0.99999983 & 1.000006464 & 1.000013098 \\
\hline 1.5 & 1.029696605 & 0.999999871 & 1.000000108 & 1.000000345 \\
\hline 2 & 1.024744024 & 1.000016052 & 1.000007914 & 0.999999777 \\
\hline \multicolumn{5}{|c|}{$45 /-45 / 45 /-45 / 45 /-45 / 45 /-45$} \\
\hline & & \multicolumn{3}{|c|}{ Delamination Size } \\
\hline Wmax/h & Intact & $8 \times 8 \mathrm{~cm}$ & $12 \times 12 \mathrm{~cm}$ & $16 \times 16 \mathrm{~cm}$ \\
\hline 0.5 & 1.017880288 & 1.002234394 & 1.011817075 & 1.021399757 \\
\hline 1 & 0.914623179 & 1.000350891 & 1.000464826 & 1.00057876 \\
\hline 1.5 & 0.8937672 & 0.999860939 & 0.999917222 & 0.999973505 \\
\hline 2 & 0.886401958 & 1.000088037 & 1.000026882 & 0.999965727 \\
\hline \multicolumn{5}{|c|}{$0 / 45 /-45 / 90 / 0 / 45 /-45 / 90$} \\
\hline & & \multicolumn{3}{|c|}{ Delamination Size } \\
\hline Wmax/h & Intact & $8 \times 8 \mathrm{~cm}$ & $12 \times 12 \mathrm{~cm}$ & $16 \times 16 \mathrm{~cm}$ \\
\hline 0.5 & 0.949228308 & 1.184628365 & 1.099631171 & 1.014633978 \\
\hline 1 & 0.881421544 & 1.08333708 & 1.041923194 & 1.000509307 \\
\hline 1.5 & 0.868473041 & 1.032707487 & 1.016366451 & 1.000025415 \\
\hline 2 & 0.863880721 & 1.000004516 & 1.000004486 & 1.000004455 \\
\hline
\end{tabular}




\section{CONCLUSIONS}

The geometrically nonlinear free vibration analysis of composite plate with and without containing the delamination is investigated using nonlinear finite element method in the framework of a higher order shear deformation theory in Green-Lagrange sense. The governing equation of the vibrated plate is derived using the Variational approach. The frequency amplitude relations for the nonlinear free vibrated plate are computed using eigenvalue formulation and are solved employing a direct iterative procedure. Based on the numerical results the following conclusions are drawn.

- The validation shows the necessities of taking into account full nonlinearity.

- The finite element model proposed can be predicted accurately the dynamic behaviors of a laminated composite plate with internal delamination at arbitrary location. Hence the discrepancy of the results was (15.8022\% with considering the nonlinearity).

- Local internal delamination has slight effect on the natural frequencies of the laminated composite plate although the extent of the natural frequency variation increases with both the delamination dimension and the order of the natural frequency.

\section{REFERENCES}

Shin DK., "Large Amplitude Vibration Behavior of Doubly Curved Shallow Shells With Simply Supported Edges", Computer Structure, Vol. (1), No. (62), pp. 35-49, 1997.

Panda S. K., Singh B. N., "Non-Linear Free Vibration of Spherical Shell Panel Using High Order Shear Deformation Theory- A Finite Element Approach", Journal of Pressure Vessels and Piping, Vol.(86), pp. 373-383, November 2009.

Reddy J. N., "Free Vibration of Antisymmetric Angle - ply Laminated Plates Including Transverse Shear Deformation By the Finite Element Method", Journal of sound and vibration, p.p. 565-576, April 1979.

Reddy J. N. and Chao W. C., "Large Deflection and Large Amplitude Free Vibrations of Laminated Composite Material Plates", Journal of Computers \& Structures, Vol. 13, pp. 341-347, April 1981.

Reddy J.N. and Liu C. F., "A High Order Shear Deformation Theory of Laminated Elastic Shells", Int. Journal Engineering Science, Vol. 23, No. 3, pp. 319330, 1985.

Shiau L. C. and Wu T. Y., "A High Precision High order Triangular Element for Free Vibration of General
Laminated Plates", Journal of Sound and Vibration, Vol. 161, No. 2, pp. 265-279, October 1991.

Malekzadeh P., "A differential Quadrature Nonlinear Free Vibration Analysis of Laminated Composite Skew Thin Plates", Journal of Thin Wall Structures, Vol. (45), pp. 237-250, January 2007.

Ganapathi M., Amit Kalyani, Bhaskar Mondal, Prakash T., "Free Vibration Analysis of Simply Supported Composite Laminated Panels", Journal of Composite Structures, Vol. (90), pp. 100-103, February 2009.

Aditi Chattopadhyay and Haozhong Gu, "Modeling of Delamination Buckling in Composite Cylindrical Shells With a New Higher Order Theory", Journal of Composite Sciences and Technology, Vol. (54), pp. 223-232, April 1995.

Hyonny Kim and Keith T. Kedward, "A Method for Modeling The Local And Global Buckling of Delaminated Composite Plates", Journal of Composite Structures, Vol. (44),pp.43-53,1999.

Liangjin Gui and Zhengneng Li, "Delamination Buckling of Stitched Laminates", Journal of Composites Science and Technology, Vol. (61),pp. 629-636, June 2000.

Heung Soo Kim, Aditi Chattopadhyay and Anindya Ghoshal, "Characterization of Delamination Effect on Composite Laminates Using a New Generalized Layerwise Approach", Journal of Computers \& Structures, Vol. (81), pp. 1555-1566, February 2003.

Dongwei Shu and Christian N. Della, "Free Vibration Analysis of Composite Beams With Two NonOverlapping Delaminations", Journal of International Mechanical Sciences, Vol. (46), pp. 509-526, May 2004.

Alberto Diaz Diaz, Jean François Caron and Alain Ehelacher, "Analytical Determination of the Mode I, II, and III Energy Release Rates in a Delaminated Laminate and Validation of a Delamination Criterion", Journal of Composite Structures, Vol. (78), pp. 424432, December 2005.

Wang X. and Dong K., "Local Buckling for Triangular And Lemniscate Delaminations Near The Surface of Laminated Cylindrical Shells Under Hygrothermal Effects", Journal of Composite Structures, Vol. (79), pp. 67-75, December 2005.

Yang J. H. and Fu Y. M., "Delamination Growth of Laminated Composite Cylindrical Shells", Journal of Theoretical and Applied Fracture Mechanics, Vol. (45), 2006.

Christian N. Della and Dongwei Shu, "Vibration of Delaminated Composite Laminates", Journal of Applied Mechanics, Vol.(60), pp. 1-20, January 2007.

Yang Jinhua, Fu Yiming and Wang Xianqiao, "Variational Analysis of Delamination Growth for Composite 
Am. J. Sci. Ind. Res., 2011, 2(2): 251-277

Laminated Cylindrical Shells Under Circumferential Concentrated Load", Journal of Composites Science and Technology, Vol. (67), pp. 541-550, 2007.

Sang Youl Lee and Dae Yong Park, "Buckling Analysis of Laminated Composite Plates Containing Delaminations Using The Enhanced Assumed Strain Solid Element", Journal of Solids and Structures, Vol. (44), pp. 8006-8027, May 2007.

Züleyha Aslan and Mustafa Şahin, "Buckling Behavior and Compressive Failure of Composite Laminates Containing Multiple Large Delaminations", Journal of Composite Structures, Vol. (89), pp. 382-390, September 2008.

Alnefaie K., "Finite Element Modeling Composite Plates With Internal Delamination", Journal of Composite Structures, Vol. (90), pp. 21-27, January 2009.
Marco Amabili, "Nonlinear Vibrations and Stability of Shells and Plates", Cambridge University Press, 2008.

Samuel Kinde Kassegne, "Layerwise Theory for Discretely Stiffened Laminated Cylindrical Shell", Virginia Polytechnic Institute and State University, Ph. D. , Thesis, December 1992.

Noor, A.K., "Force Vibration of Multilayer Composite Plates", Vol. (11), pp. 1038-1051, 1975.

R. Akkerman., "Laminate Mechanics for Balance Woven Fabrics", Journal of Composite, Vol. 37,pp.(108116),2006.

D. Gay , S. V. Hoa, S. W. Tasi, "Composite Materials Design and Application", Boca Raton, London, New York, Washington, 2003. 


\section{Appendix (A)}

The coefficients of matrix in equation (3) and equation (17)

$$
\begin{aligned}
& \varepsilon_{1}^{0}=\frac{\partial u}{\partial \alpha}+\frac{w}{R_{1}} \\
& \varepsilon_{2}^{0}=\frac{\partial v}{\partial \beta}+\frac{w}{R_{2}} \\
& \varepsilon_{6}^{0}=\frac{\partial u}{\partial \beta}+\frac{\partial v}{\partial \alpha} \\
& \varepsilon_{5}^{0}=\phi_{1}+\frac{\partial w}{\partial \alpha}-\frac{u}{R_{1}} \\
& \varepsilon_{4}^{0}=\phi_{2}+\frac{\partial w}{\partial \beta}-\frac{v}{R_{2}} \\
& \varepsilon_{1}^{4}=\left(\frac{\partial u}{\partial \alpha}\right)^{2}+\left(\frac{\partial v}{\partial \alpha}\right)^{2}+\left(\frac{\partial w}{\partial \alpha}\right)^{2}+\frac{u^{2}}{R_{1}^{2}}+\frac{w^{2}}{R_{1}^{2}}+\frac{2 w}{R_{1}} \frac{\partial u}{\partial \alpha}-\frac{2 u}{R_{1}} \frac{\partial w}{\partial \alpha} \\
& \varepsilon_{2}^{4}=\left(\frac{\partial u}{\partial \beta}\right)^{2}+\left(\frac{\partial v}{\partial \beta}\right)^{2}+\left(\frac{\partial w}{\partial \beta}\right)^{2}+\frac{v^{2}}{R_{2}^{2}}+\frac{w^{2}}{R_{2}^{2}}+\frac{2 w}{R_{2}} \frac{\partial v}{\partial \beta}-\frac{2 v}{R_{2}} \frac{\partial w}{\partial \beta} \\
& \varepsilon_{6}^{4}=\left(\frac{\partial u}{\partial \alpha}\right)\left(\frac{\partial u}{\partial \beta}\right)+\left(\frac{\partial v}{\partial \beta}\right)\left(\frac{\partial v}{\partial \alpha}\right)+\left(\frac{\partial w}{\partial \beta}\right)\left(\frac{\partial w}{\partial \alpha}\right)+\frac{2 w}{R_{1}} \frac{\partial u}{\partial \beta}+\frac{2 v u}{R_{1} R_{2}}+\frac{2 w}{R_{2}} \frac{\partial v}{\partial \alpha}-\frac{2 v}{R_{2}} \frac{\partial w}{\partial \alpha}-\frac{2 u}{R_{1}} \frac{\partial w}{\partial \beta} \\
& \varepsilon_{5}^{4}=2 \phi_{1} \frac{\partial u}{\partial \beta}+\frac{2 \phi_{2} w}{R_{2}}+2 \phi_{2} \frac{\partial v}{\partial \beta} \quad \varepsilon_{4}^{4}=2 \phi_{2} \frac{\partial v}{\partial \alpha}+\frac{2 \phi_{1} w}{R_{1}}+2 \phi_{1} \frac{\partial u}{\partial \alpha} \\
& \chi_{1}^{1}=\frac{\partial \phi_{1}}{\partial \alpha} \quad \chi_{2}^{1}=\frac{\partial \phi_{2}}{\partial \beta} \quad \chi_{6}^{1}=\frac{\partial \phi_{2}}{\partial \alpha}+\frac{\partial \phi_{1}}{\partial \beta} \\
& \chi_{5}^{1}=-\frac{\phi_{1}}{R_{1}}+2 \psi_{1} \quad \chi_{4}^{1}=-\frac{\phi_{2}}{R_{2}}+2 \psi_{2} \\
& \chi_{1}^{5}=\frac{2 u \phi_{1}}{R_{1}^{2}}+2 \frac{\partial u}{\partial \alpha} \frac{\partial \phi_{1}}{\partial \alpha}+2 \frac{\partial v}{\partial \alpha} \frac{\partial \phi_{2}}{\partial \alpha}+\frac{2 w}{R_{1}} \frac{\partial \phi_{1}}{\partial \alpha}-2 \frac{\phi_{1}}{R_{1}} \frac{\partial w}{\partial \alpha} \\
& \chi_{2}^{5}=\frac{2 v \phi_{2}}{R_{2}^{2}}+2 \frac{\partial u}{\partial \alpha} \frac{\partial \phi_{1}}{\partial \alpha}+2 \frac{\partial v}{\partial \beta} \frac{\partial \phi_{2}}{\partial \beta}+\frac{2 w}{R 2} \frac{\partial \phi_{2}}{\partial \beta}-2 \frac{\phi_{2}}{R_{2}} \frac{\partial w}{\partial \beta} \\
& \chi_{6}^{5}=2 \frac{\partial u}{\partial \alpha} \frac{\partial \phi_{1}}{\partial \beta}+2 \frac{\partial v}{\partial \alpha} \frac{\partial \phi_{2}}{\partial \beta}-2 \frac{\phi_{2}}{R_{2}} \frac{\partial w}{\partial \alpha}+2 \frac{\partial \phi_{1}}{\partial \alpha} \frac{\partial u}{\partial \beta}+\frac{2 \phi_{2} u}{R_{1} R_{2}}+\frac{2 w}{R_{2}} \frac{\partial \phi_{2}}{\partial \alpha}+\frac{2 w}{R_{1}} \frac{\partial \phi_{1}}{\partial \beta} \\
& +\frac{2 v \phi_{1}}{R_{1} R_{2}}+2 \frac{\partial \phi_{2}}{\partial \alpha} \frac{\partial v}{\partial \beta}-\frac{2 \phi_{1}}{R_{1}} \frac{\partial w}{\partial \beta} \\
& \chi_{5}^{5}=2 \phi_{1} \frac{\partial \phi_{1}}{\partial \alpha}+4 \psi_{2} \frac{\partial v}{\partial \alpha}+4 \frac{w \psi_{1}}{R_{1}}+2 \phi_{2} \frac{\partial \phi_{2}}{\partial \alpha}+4 \psi_{1} \frac{\partial u}{\partial \alpha} \\
& \chi_{4}^{5}=4 \psi_{1} \frac{\partial u}{\partial \beta}+4 \frac{\psi_{2} w}{R_{2}}+2 \phi_{2} \frac{\partial \phi_{2}}{\partial \beta}+2 \phi_{1} \frac{\partial \phi_{1}}{\partial \beta}+4 \psi_{2} \frac{\partial v}{\partial \beta} \\
& \chi_{1}^{2}=\frac{\partial \psi_{1}}{\partial \alpha} \quad \chi_{2}^{2}=\frac{\partial \psi_{2}}{\partial \beta}
\end{aligned}
$$




$$
\begin{aligned}
& \chi_{6}^{2}=\frac{\partial \psi_{2}}{\partial \alpha}+\frac{\partial \psi_{1}}{\partial \beta} \\
& \chi_{5}^{2}=3 \theta_{1}-\frac{\psi_{1}}{R_{1}} \\
& \chi_{4}^{2}=3 \theta_{2}-\frac{\psi_{2}}{R_{2}} \\
& \chi_{1}^{6}=\frac{2 w}{R_{1}} \frac{\partial \psi_{1}}{\partial \alpha}+\left(\frac{\partial \phi_{2}}{\partial \alpha}\right)^{2}+\left(\frac{\partial \phi_{1}}{\partial \alpha}\right)^{2}+2 \frac{\partial u}{\partial \alpha} \frac{\partial \psi_{1}}{\partial \alpha}+2 \frac{\partial v}{\partial \alpha} \frac{\partial \psi_{2}}{\partial \alpha}+\frac{2 u \psi_{1}}{R_{1}^{2}}+\left(\frac{\phi_{1}}{R_{1}}\right)^{2}-\frac{2 \psi_{1}}{R_{1}} \frac{\partial w}{\partial \alpha} \\
& \chi_{2}^{6}=\frac{2 w}{R_{2}} \frac{\partial \psi_{2}}{\partial \beta}+\left(\frac{\partial \phi_{2}}{\partial \beta}\right)^{2}+\left(\frac{\partial \phi_{1}}{\partial \beta}\right)^{2}+2 \frac{\partial u}{\partial \beta} \frac{\partial \psi_{1}}{\partial \beta}+2 \frac{\partial v}{\partial \beta} \frac{\partial \psi_{2}}{\partial \beta}+\frac{2 v \psi_{2}}{R_{2}^{2}}+\left(\frac{\phi_{2}}{R_{2}}\right)^{2} \\
& -\frac{2 \psi_{2}}{R_{2}} \frac{\partial w}{\partial \beta} \\
& \chi_{6}^{6}=2 \frac{\partial \phi_{2}}{\partial \alpha} \frac{\partial \phi_{2}}{\partial \beta}+2 \frac{\partial u}{\partial \alpha} \frac{\partial \psi_{1}}{\partial \beta}-\frac{2 \psi_{2}}{R_{2}} \frac{\partial w}{\partial \alpha}+2 \frac{\partial \phi_{1}}{\partial \alpha} \frac{\partial \phi_{1}}{\partial \beta}+2 \frac{\partial \psi_{2}}{\partial \alpha} \frac{\partial v}{\partial \beta}+\frac{2 w}{R_{2}} \frac{\partial \psi_{2}}{\partial \alpha} \\
& +2 \frac{\partial \psi_{1}}{\partial \alpha} \frac{\partial u}{\partial \beta}+\frac{2 \phi_{1} \phi_{2}}{R_{1} R_{2}}+\frac{2 v \psi_{1}}{R_{1} R_{2}}+\frac{2 u \psi_{2}}{R_{1} R_{2}}+\frac{2 w}{R 1} \frac{\partial \psi_{1}}{\partial \beta}+2 \frac{\partial v}{\partial \alpha} \frac{\partial \psi_{2}}{\partial \beta}-\frac{2 \psi_{1}}{R_{1}} \frac{\partial w}{\partial \beta} \\
& \chi_{5}^{6}=2 \phi_{2} \frac{\partial \psi_{2}}{\partial \alpha}+2 \phi_{1} \frac{\partial \psi_{1}}{\partial \alpha}+6 \theta_{1} \frac{\partial u}{\partial \alpha}+\frac{6 w \theta_{1}}{R_{1}}+4 \psi_{2} \frac{\partial \phi_{2}}{\partial \alpha}+4 \psi_{1} \frac{\partial \phi_{1}}{\partial \alpha}+6 \theta_{2} \frac{\partial v}{\partial \alpha} \\
& \chi_{4}^{6}=2 \phi_{2} \frac{\partial \psi_{2}}{\partial \beta}+2 \phi_{1} \frac{\partial \psi_{1}}{\partial \beta}+6 \theta_{1} \frac{\partial u}{\partial \beta}+\frac{6 w \theta_{2}}{R_{2}}+4 \psi_{2} \frac{\partial \phi_{2}}{\partial \beta}+4 \psi_{1} \frac{\partial \phi_{1}}{\partial \beta}+6 \theta_{2} \frac{\partial v}{\partial \beta} \\
& \chi_{1}^{3}=\frac{\partial \theta_{1}}{\partial \alpha} \quad \chi_{2}^{3}=\frac{\partial \theta_{2}}{\partial \beta} \quad \chi_{6}^{3}=\frac{\partial \theta_{1}}{\partial \beta}+\frac{\partial \theta_{2}}{\partial \alpha} \\
& \chi_{5}^{3}=-\frac{\theta_{1}}{R_{1}} \quad \chi_{4}^{3}=-\frac{\theta_{2}}{R_{2}} \\
& \chi_{1}^{7}=2 \frac{\partial \phi_{1}}{\partial \alpha} \frac{\partial \psi_{1}}{\partial \alpha}+2 \frac{w}{R_{1}} \frac{\partial \theta_{1}}{\partial \alpha}+\frac{2 \phi_{1} \psi_{1}}{R_{1}^{2}}-\frac{2 \theta_{1}}{R_{1}} \frac{\partial w}{\partial \alpha}+2 \frac{\partial u}{\partial \alpha} \frac{\partial \theta_{1}}{\partial \alpha}+2 \frac{\partial \phi_{2}}{\partial \alpha} \frac{\partial \psi_{2}}{\partial \alpha} \\
& 2 \frac{\partial v}{\partial \alpha} \frac{\partial \theta_{2}}{\partial \alpha}+\frac{2 u \theta_{1}}{R_{1}^{2}} \\
& \chi_{2}^{7}=\frac{2 w}{R_{2}} \frac{\partial \theta_{2}}{\partial \beta}+2 \frac{\partial u}{\partial \beta} \frac{\partial \theta_{1}}{\partial \beta}+2 \frac{\partial v}{\partial \beta} \frac{\partial \theta_{2}}{\partial \beta}+2 \frac{\partial \phi_{1}}{\partial \beta} \frac{\partial \psi_{1}}{\partial \beta}-\frac{2 \theta_{2}}{R_{2}} \frac{\partial w}{\partial \beta}+\frac{2 v \theta_{2}}{R_{1}^{2}}+2 \frac{\partial \phi_{2}}{\partial \beta} \frac{\partial \psi_{2}}{\partial \beta} \\
& +\frac{2 \phi_{2} \psi_{2}}{R_{1}^{2}} \\
& \chi_{6}^{7}=2 \frac{\partial u}{\partial \alpha} \frac{\partial \theta_{1}}{\partial \beta}+2 \frac{\partial \theta_{2}}{\partial \alpha} \frac{\partial v}{\partial \beta}+2 \frac{\partial \theta_{1}}{\partial \alpha} \frac{\partial u}{\partial \beta}+2 \frac{\partial \psi_{1}}{\partial \alpha} \frac{\partial \phi_{1}}{\partial \beta}+2 \frac{\partial \phi_{1}}{\partial \alpha} \frac{\partial \psi_{1}}{\partial \beta}+2 \frac{\partial v}{\partial \alpha} \frac{\partial \theta_{2}}{\partial \beta} \\
& +2 \frac{\partial \phi_{2}}{\partial \alpha} \frac{\partial \psi_{2}}{\partial \beta}+2 \frac{\partial \psi_{2}}{\partial \alpha} \frac{\partial \phi_{2}}{\partial \beta}-\frac{2 \theta_{2}}{R_{2}} \frac{\partial w}{\partial \alpha}+\frac{2 \theta_{2} u}{R_{1} R_{2}}+\frac{2 w}{R_{2}} \frac{\partial \theta_{2}}{\partial \alpha}-\frac{2 \theta_{1}}{R_{1}} \frac{\partial w}{\partial \beta}+\frac{2 \psi_{2} \phi_{1}}{R_{1} R_{2}}
\end{aligned}
$$




$$
\begin{aligned}
& +\frac{2 v \theta_{1}}{R_{1} R_{2}}+\frac{\phi_{2} \psi_{1}}{R_{1} R_{2}}+\frac{2 w}{R_{1}} \frac{\partial \theta_{1}}{\partial \beta} \\
& \chi_{5}^{7}=4 \psi_{1} \frac{\partial \psi_{1}}{\partial \alpha}+2 \phi_{1} \frac{\partial \theta_{1}}{\partial \alpha}+6 \theta_{2} \frac{\partial \phi_{2}}{\partial \alpha}+6 \theta_{1} \frac{\partial \phi_{1}}{\partial \alpha}+2 \phi_{2} \frac{\partial \theta_{2}}{\partial \alpha}+4 \psi_{2} \frac{\partial \psi_{2}}{\partial \alpha} \\
& \chi_{4}^{7}=4 \psi_{2} \frac{\partial \psi_{2}}{\partial \beta}+2 \phi_{2} \frac{\partial \theta_{2}}{\partial \beta}+4 \psi_{1} \frac{\partial \psi_{1}}{\partial \beta}+2 \phi_{1} \frac{\partial \theta_{1}}{\partial \beta}+6 \theta_{2} \frac{\partial \phi_{2}}{\partial \beta}+6 \theta_{1} \frac{\partial \phi_{1}}{\partial \beta} \\
& \chi_{1}^{8}=2 \frac{\partial \phi_{1}}{\partial \alpha} \frac{\partial \theta_{1}}{\partial \alpha}+\left(\frac{\partial \psi_{2}}{\partial \alpha}\right)^{2}+\frac{2 \phi_{1} \theta_{1}}{R_{1}^{2}}+2 \frac{\partial \phi_{2}}{\partial \alpha} \frac{\partial \theta_{2}}{\partial \alpha}+\left(\frac{\partial \psi_{1}}{\partial \alpha}\right)^{2}+\left(\frac{\psi_{1}}{R_{1}}\right)^{2} \\
& \chi_{2}^{8}=2 \frac{\partial \phi_{1}}{\partial \beta} \frac{\partial \theta_{1}}{\partial \beta}+\left(\frac{\partial \psi_{2}}{\partial \beta}\right)^{2}+\frac{2 \phi_{2} \theta_{2}}{R_{2}^{2}}+2 \frac{\partial \phi_{2}}{\partial \beta} \frac{\partial \theta_{2}}{\partial \beta}+\left(\frac{\partial \psi_{1}}{\partial \beta}\right)^{2}+\left(\frac{\psi_{2}}{R_{2}}\right)^{2} \\
& \chi_{6}^{8}=\frac{2 \phi_{2} \theta_{1}}{R_{1} R_{2}}+2 \frac{\partial \psi_{2}}{\partial \alpha} \frac{\partial \psi_{2}}{\partial \beta}+2 \frac{\partial \theta_{2}}{\partial \alpha} \frac{\partial \phi_{2}}{\partial \beta}+2 \frac{\partial \theta_{1}}{\partial \alpha} \frac{\partial \phi_{1}}{\partial \beta}+\frac{2 \psi_{2} \psi_{1}}{R_{1} R_{2}}+2 \frac{\partial \psi_{1}}{\partial \alpha} \frac{\partial \psi_{1}}{\partial \beta} \\
& 2 \frac{\partial \phi_{2}}{\partial \alpha} \frac{\partial \theta_{2}}{\partial \beta}+\frac{2 \theta_{2} \phi_{1}}{R_{1} R_{2}}+2 \frac{\partial \phi_{1}}{\partial \alpha} \frac{\partial \theta_{1}}{\partial \beta} \\
& 2 \chi_{5}^{8}=4 \psi_{2} \frac{\partial \theta_{2}}{\partial \alpha}+6 \theta_{1} \frac{\partial \psi_{1}}{\partial \alpha}+4 \psi_{1} \frac{\partial \theta_{1}}{\partial \alpha}+6 \theta_{2} \frac{\partial \psi_{2}}{\partial \alpha} \\
& 2 \chi_{4}^{8}=4 \psi_{2} \frac{\partial \theta_{2}}{\partial \beta}+6 \theta_{1} \frac{\partial \psi_{1}}{\partial \beta}+4 \psi_{1} \frac{\partial \theta_{1}}{\partial \beta}+6 \theta_{2} \frac{\partial \psi_{2}}{\partial \beta} \\
& \chi_{1}^{9}=\frac{2 \psi_{1} \theta_{1}}{R_{1}^{2}}+\frac{\partial \psi_{2}}{\partial \alpha} \frac{\partial \theta_{2}}{\partial \alpha}+2 \frac{\partial \psi_{1}}{\partial \alpha} \frac{\partial \theta_{1}}{\partial \alpha} \\
& \chi_{2}^{9}=\frac{2 \psi_{2} \theta_{2}}{R_{2}^{2}}+\frac{\partial \psi_{2}}{\partial \beta} \frac{\partial \theta_{2}}{\partial \beta}+2 \frac{\partial \psi_{1}}{\partial \beta} \frac{\partial \theta_{1}}{\partial \beta} \\
& 2 \chi_{6}^{9}=\frac{\psi_{2} \theta_{1}}{R_{1} R_{2}}+2 \frac{\partial \theta_{2}}{\partial \alpha} \frac{\partial \psi_{2}}{\partial \beta}+2 \frac{\partial \theta_{1}}{\partial \alpha} \frac{\partial \psi_{1}}{\partial \beta}+2 \frac{\partial \psi_{2}}{\partial \alpha} \frac{\partial \theta_{2}}{\partial \beta}+\frac{2 \theta_{2} \psi_{1}}{R_{1} R_{2}}+2 \frac{\partial \psi_{1}}{\partial \alpha} \frac{\partial \theta_{1}}{\partial \beta} \\
& 2 \chi_{5}^{9}=6 \theta_{2} \frac{\partial \theta_{2}}{\partial \alpha}+6 \theta_{1} \frac{\partial \theta_{1}}{\partial \alpha} \\
& 2 \chi_{5}^{9}=6 \theta_{2} \frac{\partial \theta_{2}}{\partial \beta}+6 \theta_{1} \frac{\partial \theta_{1}}{\partial \beta} \\
& \chi_{1}^{10}=\left(\frac{\theta_{1}}{R_{1}}\right)^{2}+\left(\frac{\partial \theta_{2}}{\partial \alpha}\right)^{2}+\left(\frac{\partial \theta_{1}}{\partial \alpha}\right)^{2} \\
& \chi_{2}^{10}=\left(\frac{\theta_{2}}{R_{2}}\right)^{2}+\left(\frac{\partial \theta_{2}}{\partial \beta}\right)^{2}+\left(\frac{\partial \theta_{1}}{\partial \beta}\right)^{2} \\
& 2 \chi_{6}^{10}=2 \frac{\partial \theta_{2}}{\partial \alpha} \frac{\partial \theta_{2}}{\partial \beta}+2 \frac{\partial \theta_{1}}{\partial \alpha} \frac{\partial \theta_{1}}{\partial \alpha}+\frac{2 \theta_{1} \theta_{2}}{R_{1} R_{2}}
\end{aligned}
$$




\section{For Delamination terms}

$$
\begin{aligned}
& \varepsilon_{d 1}^{0}=\left(\frac{\partial U^{\prime}}{\partial \alpha}+\frac{W^{\prime}}{R_{1}}\right) \times H^{\prime}(z) \\
& \varepsilon_{d 2}^{0}=\left(\frac{\partial V^{\prime}}{\partial \beta}+\frac{W^{\prime}}{R_{2}}\right) \times H^{\prime}(z) \\
& \varepsilon_{d 6}^{0}=\left(\frac{\partial U^{\prime}}{\partial \beta}+\frac{\partial V^{\prime}}{\partial \alpha}\right) \times H^{\prime}(z) \\
& \varepsilon_{d 5}^{0}=\left(-\frac{U^{\prime}}{R_{1}}\right) \times H^{\prime}(z) \\
& \varepsilon_{d 4}^{0}=\left(-\frac{V^{\prime}}{R_{2}}\right) \times H^{\prime}(z) \\
& \varepsilon_{d 1}^{4}=\left(\frac{2 W^{\prime}}{R_{1}} \frac{\partial U^{\prime}}{\partial \alpha}+\left(\frac{\partial W^{\prime}}{\partial \alpha}\right)^{2}+\left(\frac{U^{\prime}}{R_{1}}\right)^{2}+\left(\frac{\partial V^{\prime}}{\partial \alpha}\right)^{2}-\frac{2 U^{\prime}}{R_{1}} \frac{\partial W^{\prime}}{\partial \alpha}+\left(\frac{\partial U^{\prime}}{\partial \alpha}\right)^{2}+\left(\frac{W^{\prime}}{R_{1}}\right)^{2}\right) \times H(z)^{2} \\
& \left(2 \frac{\partial w}{\partial \alpha} \frac{\partial W^{\prime}}{\partial \alpha}+\frac{2 w}{R_{1}} \frac{\partial U^{\prime}}{\partial \alpha}+\frac{2 u U^{\prime}}{R_{1}^{2}}+\frac{2 w W^{\prime}}{R_{1}^{2}}+\frac{2 W^{\prime}}{R_{1}} \frac{\partial u}{\partial \alpha}+2 \frac{\partial u}{\partial \alpha} \frac{\partial U^{\prime}}{\partial \alpha}-\frac{2 u}{R_{1}} \frac{\partial W^{\prime}}{\partial \alpha}\right. \\
& \left.+\frac{\partial v}{\partial \alpha} \frac{\partial V^{\prime}}{\partial \alpha}-\frac{2 U^{\prime}}{R_{1}} \frac{\partial w}{\partial \alpha}\right) \times H(z) \\
& \varepsilon_{d 2}^{4}=\left(\left(\frac{V^{\prime}}{R_{2}}\right)^{2}+\left(\frac{\partial V^{\prime}}{\partial \beta}\right)^{2}+\left(\frac{\partial U^{\prime}}{\partial \beta}\right)^{2}+\left(\frac{W^{\prime}}{R_{2}}\right)^{2}+\left(\frac{2 W^{\prime}}{R_{2}} \frac{\partial V^{\prime}}{\partial \beta}\right)+\left(\frac{\partial W^{\prime}}{\partial \beta}\right)^{2}-\frac{2 V^{\prime}}{R_{2}} \frac{\partial W^{\prime}}{\partial \beta}\right) \times H(z)^{2} \\
& \left(2 \frac{\partial w}{\partial \beta} \frac{\partial W^{\prime}}{\partial \beta}+2 \frac{\partial u}{\partial \beta} \frac{\partial U^{\prime}}{\partial \beta}+\frac{2 w}{R_{2}} \frac{\partial V^{\prime}}{\partial \beta}+\frac{2 v V^{\prime}}{R_{2}^{2}}+2 \frac{\partial v}{\partial \beta} \frac{\partial V^{\prime}}{\partial \beta}-\frac{2 V^{\prime}}{R_{2}} \frac{\partial w}{\partial \beta}+\frac{2 w W^{\prime}}{R_{2}^{2}}\right. \\
& \left.+\frac{2 W^{\prime}}{R_{2}} \frac{\partial v}{\partial \beta}-\frac{2 v}{R_{2}} \frac{\partial W^{\prime}}{\partial \beta}\right) \times H(z) \\
& \varepsilon_{d 6}^{4}=\left(\frac{2 V^{\prime} U^{\prime}}{R_{2} R_{1}}+2 \frac{\partial W^{\prime}}{\partial \alpha} \frac{\partial W^{\prime}}{\partial \beta}-\frac{2 V^{\prime}}{R_{2}} \frac{\partial W^{\prime}}{\partial \alpha}-\frac{2 U^{\prime}}{R_{1}} \frac{\partial W^{\prime}}{\partial \beta}+\frac{\partial U^{\prime}}{\partial \alpha} \frac{\partial U^{\prime}}{\partial \beta}+\frac{2 W^{\prime}}{R_{2}} \frac{\partial V^{\prime}}{\partial \alpha}\right. \\
& \left.+\frac{2 W^{\prime}}{R_{1}} \frac{\partial U^{\prime}}{\partial \beta}+2 \frac{\partial V^{\prime}}{\partial \alpha} \frac{\partial V^{\prime}}{\partial \beta}\right) \times H(z)^{2}+\left(2 \frac{\partial v}{\partial \alpha} \frac{\partial V^{\prime}}{\partial \beta}+\frac{2 w}{R_{2}} \frac{\partial V^{\prime}}{\partial \alpha}+\frac{2 v U^{\prime}}{R_{1} R_{2}}+2 \frac{\partial U^{\prime}}{\partial \alpha} \frac{\partial u}{\partial \beta}\right. \\
& +2 \frac{\partial w}{\partial \alpha} \frac{\partial W^{\prime}}{\partial \beta}-\frac{2 V^{\prime}}{R_{2}} \frac{\partial w}{\partial \alpha}+\frac{2 W^{\prime}}{R_{1}} \frac{\partial u}{\partial \beta}+\frac{2 w}{R_{1}} \frac{\partial U^{\prime}}{\partial \beta}+2 \frac{\partial u}{\partial \alpha} \frac{\partial U^{\prime}}{\partial \beta}+\frac{2 W^{\prime}}{R_{2}} \frac{\partial v}{\partial \alpha} \\
& \left.+2 \frac{\partial W^{\prime}}{\partial \alpha} \frac{\partial w}{\partial \beta}-\frac{2 U^{\prime}}{R_{1}} \frac{\partial w}{\partial \beta}+\frac{2 u V^{\prime}}{R_{1} R_{2}}-\frac{2 v}{R_{2}} \frac{\partial W^{\prime}}{\partial \alpha}-\frac{2 u}{R_{1}} \frac{\partial W^{\prime}}{\partial \beta}+2 \frac{\partial V^{\prime}}{\partial \alpha} \frac{\partial v}{\partial \beta}\right) \times H(z) \\
& \varepsilon_{d 5}^{4}=\left(2 \phi_{1} \frac{\partial U^{\prime}}{\partial \alpha}+\frac{2 \phi_{1} W^{\prime}}{R_{1}}+2 \phi_{2} \frac{\partial V^{\prime}}{\partial \alpha}\right) \times H(z) \\
& \varepsilon_{d 4}^{4}=\left(2 \phi_{1} \frac{\partial U^{\prime}}{\partial \beta}+\frac{2 \phi_{2} W^{\prime}}{R_{2}}+2 \phi_{2} \frac{\partial V^{\prime}}{\partial \beta}\right) \times H(z)
\end{aligned}
$$




$$
\begin{aligned}
& \chi_{d 1}^{5}=\left(\frac{2 \phi_{1} U^{\prime}}{R_{1}^{2}}-\frac{2 \phi_{1}}{R_{1}} \frac{\partial W^{\prime}}{\partial \alpha}+\frac{2 W^{\prime}}{R_{1}} \frac{\partial \phi_{1}}{\partial \alpha}+2 \frac{\partial \phi_{1}}{\partial \alpha} \frac{\partial U^{\prime}}{\partial \alpha}+2 \frac{\partial \phi_{2}}{\partial \alpha} \frac{\partial V^{\prime}}{\partial \alpha}\right) \times H(z) \\
& \chi_{d 2}^{5}=\left(\frac{2 \phi_{2} V^{\prime}}{R_{2}^{2}}-\frac{2 \phi_{2}}{R_{2}} \frac{\partial W^{\prime}}{\partial \beta}+\frac{2 W^{\prime}}{R_{2}} \frac{\partial \phi_{2}}{\partial \beta}+2 \frac{\partial \phi_{1}}{\partial \beta} \frac{\partial U^{\prime}}{\partial \beta}+2 \frac{\partial \phi_{2}}{\partial \beta} \frac{\partial V^{\prime}}{\partial \beta}\right) \times H(z) \\
& \chi_{d 6}^{5}=\left(\frac{2 \phi_{2} U^{\prime}}{R_{1} R_{2}}+\frac{2 \phi_{1} V^{\prime}}{R_{1} R_{2}}+\frac{2 W^{\prime}}{R_{1}} \frac{\partial \phi_{1}}{\partial \beta}+2 \frac{\partial U^{\prime}}{\partial \alpha} \frac{\partial \phi_{1}}{\partial \beta}+\frac{2 W^{\prime}}{R_{2}} \frac{\partial \phi_{2}}{\partial \alpha}-\frac{2 \phi_{1}}{R_{1}} \frac{\partial W^{\prime}}{\partial \beta}\right. \\
& \left.2 \frac{\partial \phi_{2}}{\partial \alpha} \frac{\partial V^{\prime}}{\partial \beta}-\frac{2 \phi_{2}}{R_{2}} \frac{\partial W^{\prime}}{\partial \alpha}+2 \frac{\partial V^{\prime}}{\partial \alpha} \frac{\partial \phi_{2}}{\partial \beta}+2 \frac{\partial \phi_{1}}{\partial \alpha} \frac{\partial U^{\prime}}{\partial \beta}\right) \times H(z) \\
& \chi_{d 5}^{5}=\left(2 \psi_{2} \frac{\partial V^{\prime}}{\partial \alpha}+\frac{4 \psi_{1} W^{\prime}}{R_{1}}+4 \psi_{1} \frac{\partial U^{\prime}}{\partial \alpha}\right) \times H(z) \\
& \chi_{d 5}^{5}=\left(2 \psi_{2} \frac{\partial V^{\prime}}{\partial \beta}+\frac{4 \psi_{2} W^{\prime}}{R_{2}}+4 \psi_{1} \frac{\partial U^{\prime}}{\partial \beta}\right) \times H(z) \\
& \chi_{d 1}^{6}=\left(\frac{2 \psi_{1} U^{\prime}}{R_{1}^{2}}-\frac{2 \psi_{1}}{R_{1}} \frac{\partial W^{\prime}}{\partial \alpha}+\frac{2 W^{\prime}}{R_{1}} \frac{\partial \psi_{1}}{\partial \alpha}+2 \frac{\partial \psi_{1}}{\partial \alpha} \frac{\partial U^{\prime}}{\partial \alpha}+2 \frac{\partial \psi_{2}}{\partial \alpha} \frac{\partial V^{\prime}}{\partial \alpha}\right) \times H(z) \\
& \chi_{d 2}^{6}=\left(\frac{2 \psi_{2} V^{\prime}}{R_{2}^{2}}-\frac{2 \psi_{2}}{R_{2}} \frac{\partial W^{\prime}}{\partial \beta}+\frac{2 W^{\prime}}{R_{2}} \frac{\partial \psi_{2}}{\partial \beta}+2 \frac{\partial \psi_{1}}{\partial \beta} \frac{\partial U^{\prime}}{\partial \beta}+2 \frac{\partial \psi_{2}}{\partial \beta} \frac{\partial V^{\prime}}{\partial \beta}\right) \times H(z) \\
& \chi_{d 6}^{6}=\left(2 \frac{\partial \psi_{1}}{\partial \beta} \frac{\partial U^{\prime}}{\partial \alpha}-\frac{2 \psi_{1}}{R_{1}} \frac{\partial W^{\prime}}{\partial \beta}+\frac{\partial \psi_{2}}{\partial \alpha} \frac{\partial V^{\prime}}{\partial \beta}+\frac{2 \psi_{1} V^{\prime}}{R_{1} R_{2}}+\frac{2 \psi_{2} U^{\prime}}{R_{1} R_{2}}+2 \frac{\partial \psi_{2}}{\partial \beta} \frac{\partial V^{\prime}}{\partial \alpha}\right. \\
& \left.+\frac{2 W^{\prime}}{R_{2}} \frac{\partial \psi_{2}}{\partial \alpha}+2 \frac{\partial \psi_{1}}{\partial \alpha} \frac{\partial U^{\prime}}{\partial \beta}+\frac{2 W^{\prime}}{R_{1}} \frac{\partial \psi_{1}}{\partial \beta}-\frac{2 \psi_{2}}{R_{2}} \frac{\partial W^{\prime}}{\partial \alpha}\right) \times H(z) \\
& \chi_{d 5}^{6}=\left(6 \theta_{2} \frac{\partial V^{\prime}}{\partial \alpha}+\frac{6 \theta_{1} W^{\prime}}{R_{1}}+6 \theta_{1} \frac{\partial U^{\prime}}{\partial \alpha}\right) \times H(z) \\
& \chi_{d 4}^{6}=\left(6 \theta_{2} \frac{\partial V^{\prime}}{\partial \beta}+\frac{6 \theta_{2} W^{\prime}}{R_{2}}+6 \theta_{1} \frac{\partial U^{\prime}}{\partial \beta}\right) \times H(z) \\
& 2 \chi_{d 1}^{7}=\left(2 \frac{\partial \theta_{2}}{\partial \alpha} \frac{\partial V^{\prime}}{\partial \alpha}+\frac{2 W^{\prime}}{R_{1}} \frac{\partial \theta_{1}}{\partial \alpha}-\frac{2 \theta_{1}}{R_{1}} \frac{\partial W^{\prime}}{\partial \alpha}+\frac{2 \theta_{1} U^{\prime}}{R_{1}^{2}}+2 \frac{\partial \theta_{1}}{\partial \alpha} \frac{\partial U^{\prime}}{\partial \alpha}\right) \times H(z) \\
& 2 \chi_{d 2}^{7}=\left(2 \frac{\partial \theta_{2}}{\partial \beta} \frac{\partial V^{\prime}}{\partial \beta}+\frac{2 W^{\prime}}{R_{2}} \frac{\partial \theta_{2}}{\partial \beta}-\frac{2 \theta_{2}}{R_{2}} \frac{\partial W^{\prime}}{\partial \beta}+\frac{2 \theta_{2} V^{\prime}}{R_{2}^{2}}+2 \frac{\partial \theta_{1}}{\partial \beta} \frac{\partial U^{\prime}}{\partial \beta}\right) \times H(z) \\
& 2 \chi_{d 6}^{7}=\left(2 \frac{\theta_{1} V^{\prime}}{R_{1} R_{2}}-\frac{2 \theta_{2}}{R_{2}} \frac{\partial W^{\prime}}{\partial \alpha}+2 \frac{\partial \theta_{1}}{\partial \alpha} \frac{\partial U^{\prime}}{\partial \beta}+2 \frac{\partial \theta_{1}}{\partial \beta} \frac{\partial U^{\prime}}{\partial \alpha}+\frac{2 \theta_{2} U^{\prime}}{R_{1} R_{2}}+2 \frac{\partial \theta_{2}}{\partial \alpha} \frac{\partial V^{\prime}}{\partial \beta}+2 \frac{\partial \theta_{1}}{\partial \beta} \frac{\partial V^{\prime}}{\partial \alpha}\right. \\
& \left.+\frac{2 W^{\prime}}{R_{1}} \frac{\partial \theta_{1}}{\partial \alpha}+\frac{2 W^{\prime}}{R_{2}} \frac{\partial \theta_{2}}{\partial \alpha}-\frac{2 \theta_{1}}{R_{1}} \frac{\partial W^{\prime}}{\partial \beta}\right) \times H(z)
\end{aligned}
$$




\section{Appendix (B)}

Coefficients of matrix $\left[B_{L}\right]$ and $\left[B_{N L}\right]$ for each node in equation (12)

B-1 The coefficients of matrix $\left[B_{L}\right]$
$B_{L}(1,1)=\frac{\partial N_{i}}{\partial \alpha}$
$B_{L}(1,3)=\frac{N_{i}}{R_{1}}$
$B_{L}(2,2)=\frac{\partial N_{i}}{\partial \beta}$
$B_{L}(2,3)=\frac{N_{i}}{R_{2}}$
$B_{L}(3,1)=\frac{\partial N_{i}}{\partial \beta}$
$B_{L}(3,2)=\frac{\partial N_{i}}{\partial \alpha}$
$B_{L}(4,1)=-\frac{N_{i}}{R_{1}}$
$B_{L}(4,3)=\frac{\partial N_{i}}{\partial \alpha}$
$B_{L}(4,4)=N_{i}$
$B_{L}(5,2)=-\frac{N_{i}}{R_{2}}$
$B_{L}(5,3)=\frac{\partial N_{i}}{\partial \beta}$
$B_{L}(5,5)=N_{i}$
$B_{L}(6,4)=\frac{\partial N_{i}}{\partial \alpha}$
$B_{L}(7,5)=\frac{\partial N_{i}}{\partial \beta}$
$B_{L}(8,4)=\frac{\partial N_{i}}{\partial \beta}$
$B_{L}(8,5)=\frac{\partial N_{i}}{\partial \alpha}$
$B_{L}(9,4)=-\frac{N_{i}}{R_{1}}$
$B_{L}(9,6)=2 \times N_{i}$
$B_{L}(10,5)=-\frac{N_{i}}{R_{2}}$
$B_{L}(10,7)=2 \times N_{i}$
$B_{L}(11,6)=\frac{\partial N_{i}}{\partial \alpha}$
$B_{L}(12,7)=\frac{\partial N_{i}}{\partial \beta}$
$B_{L}(13,6)=\frac{\partial N_{i}}{\partial \beta}$
$B_{L}(13,7)=\frac{\partial N_{i}}{\partial \alpha}$
$B_{L}(14,6)=-\frac{N_{i}}{R_{1}}$
$B_{L}(14,8)=3 \times N_{i}$
$B_{L}(15,7)=-\frac{N_{i}}{R_{2}}$
$B_{L}(15,9)=3 \times N_{i}$
$B_{L}(16,8)=\frac{\partial N_{i}}{\partial \alpha}$
$B_{L}(17,9)=\frac{\partial N_{i}}{\partial \beta}$
$B_{L}(18,8)=\frac{\partial N_{i}}{\partial \beta}$
$B_{L}(18,9)=\frac{\partial N_{i}}{\partial \alpha}$
$B_{L}(19,8)=-\frac{N_{i}}{R_{1}}$
$B_{L}(20,9)=-\frac{N_{i}}{R_{2}}$

B-2 The coefficients of matrix $\left[B_{N L}\right]$
$B_{N L}(1,1)=\left(\frac{\partial N_{i}}{\partial \alpha}\right)^{2} u_{i}+\left(\frac{\partial N_{i}}{\partial \alpha}\right)\left(\frac{w_{i}}{R_{1}}\right)$
$B_{N L}(1,2)=\left(\frac{\partial N_{i}}{\partial \alpha}\right)^{2} v_{i}$
$B_{N L}(1,3)=\left(\frac{\partial N_{i}}{\partial \alpha}\right)^{2} w_{i}+\left(\frac{\partial N_{i}}{\partial \alpha}\right)\left(\frac{u_{i}}{R_{1}}\right)$
$B_{N L}(2,1)=\left(\frac{\partial N_{i}}{\partial \beta}\right)^{2} u_{i}$ 


$$
\begin{aligned}
& B_{N L}(2,2)=\left(\frac{\partial N_{i}}{\partial \beta}\right)^{2} v_{i}+\left(\frac{\partial N_{i}}{\partial \beta}\right)\left(\frac{w_{i}}{R_{2}}\right) \quad B_{N L}(2,3)=\left(\frac{\partial N_{i}}{\partial \beta}\right)^{2} w_{i}+\left(\frac{\partial N_{i}}{\partial \beta}\right)\left(\frac{v_{i}}{R_{2}}\right) \\
& B_{N L}(3,1)=2\left(\frac{\partial N_{i}}{\partial \alpha}\right)\left(\frac{\partial N_{i}}{\partial \beta}\right) u_{i}+\left(\frac{\partial N_{i}}{\partial \beta}\right)\left(\frac{w_{i}}{R_{1}}\right) \\
& B_{N L}(3,2)=2\left(\frac{\partial N_{i}}{\partial \alpha}\right)\left(\frac{\partial N_{i}}{\partial \beta}\right) v_{i}+\left(\frac{\partial N_{i}}{\partial \alpha}\right)\left(\frac{w_{i}}{R_{2}}\right) \\
& B_{N L}(3,3)=2\left(\frac{\partial N_{i}}{\partial \alpha}\right)\left(\frac{\partial N_{i}}{\partial \beta}\right) w_{i}+\left(\frac{\partial N_{i}}{\partial \alpha}\right)\left(\frac{v_{i}}{R_{2}}\right)+\left(\frac{\partial N_{i}}{\partial \beta}\right)\left(\frac{u_{i}}{R_{1}}\right) \\
& B_{N L}(4,1)=\left(\frac{\partial N_{i}}{\partial \alpha}\right) \phi_{1 i} \quad B_{N L}(4,2)=\left(\frac{\partial N_{i}}{\partial \alpha}\right) \phi_{2 i} \\
& B_{N L}(4,3)=\frac{\phi_{1 i}}{R_{1}} \quad B_{N L}(4,4)=\left(\frac{\partial N_{i}}{\partial \alpha}\right) u_{i} \\
& B_{N L}(4,2)=\left(\frac{\partial N_{i}}{\partial \beta}\right) v_{i} \quad B_{N L}(5,1)=\left(\frac{\partial N_{i}}{\partial \beta}\right) \phi_{1 i} \\
& B_{N L}(5,2)=\left(\frac{\partial N_{i}}{\partial \beta}\right) \phi_{2 i} \quad B_{N L}(5,3)=\frac{\phi_{2 i}}{R_{2}} \\
& B_{N L}(5,4)=\left(\frac{\partial N_{i}}{\partial \beta}\right) u_{i} \quad B_{N L}(5,5)=\left(\frac{\partial N_{i}}{\partial \beta}\right) v_{i} \\
& B_{N L}(6,1)=\left(\frac{\partial N_{i}}{\partial \alpha}\right)^{2} \phi_{1 i}+\left(\frac{\phi_{1 i}}{R_{1}^{2}}\right) \quad B_{N L}(6,2)=\left(\frac{\partial N_{i}}{\partial \alpha}\right)^{2} \phi_{2 i} \\
& B_{N L}(6,3)=2\left(\frac{\partial N_{i}}{\partial \alpha}\right)\left(\frac{\phi_{1 i}}{R_{1}}\right) \quad B_{N L}(6,4)=\left(\frac{\partial N_{i}}{\partial \alpha}\right)^{2} u_{i}+\left(\frac{\partial N_{i}}{\partial \alpha}\right)\left(\frac{w_{i}}{R_{1}}\right) \\
& B_{N L}(6,5)=\left(\frac{\partial N_{i}}{\partial \alpha}\right)^{2} v_{i} \quad B_{N L}(7,1)=\left(\frac{\partial N_{i}}{\partial \beta}\right)^{2} \phi_{1 i} \\
& B_{N L}(7,2)=\left(\frac{\partial N_{i}}{\partial \beta}\right)^{2} \phi_{2 i}-\left(\frac{\phi_{2 i}}{R_{2}^{2}}\right) \quad B_{N L}(7,4)=\left(\frac{\partial N_{i}}{\partial \beta}\right)^{2} u_{i} \\
& B_{N L}(7,5)=\left(\frac{\partial N_{i}}{\partial \beta}\right)^{2} v_{i}+\left(\frac{\partial N_{i}}{\partial \beta}\right)\left(\frac{w_{i}}{R_{2}}\right) \quad B_{N L}(8,1)=2\left(\frac{\partial N_{i}}{\partial \alpha}\right)\left(\frac{\partial N_{i}}{\partial \beta}\right) \phi_{1 i}-\left(\frac{\phi_{2 i}}{R_{1} \times R_{2}}\right) \\
& B_{N L}(8,2)=2\left(\frac{\partial N_{i}}{\partial \alpha}\right)\left(\frac{\partial N_{i}}{\partial \beta}\right) \phi_{2 i}-\left(\frac{\phi_{1 i}}{R_{1} \times R_{2}}\right) \\
& B_{N L}(8,4)=2\left(\frac{\partial N_{i}}{\partial \alpha}\right)\left(\frac{\partial N_{i}}{\partial \beta}\right) u_{i}-\left(\frac{\partial N_{i}}{\partial \beta}\right)\left(\frac{w_{i}}{R_{1}}\right)
\end{aligned}
$$




$$
\begin{aligned}
& B_{N L}(8,5)=2\left(\frac{\partial N_{i}}{\partial \alpha}\right)\left(\frac{\partial N_{i}}{\partial \beta}\right) v_{i}-\left(\frac{\partial N_{i}}{\partial \alpha}\right)\left(\frac{w_{i}}{R_{2}}\right) \\
& B_{N L}(9,1)=\left(\frac{\partial N_{i}}{\partial \alpha}\right) \psi_{1 i} \\
& B_{N L}(9,2)=\left(\frac{\partial N_{i}}{\partial \alpha}\right) \psi_{2 i} \\
& B_{N L}(9,3)=2 \frac{\psi_{1 i}}{R_{1}} \\
& B_{N L}(9,4)=2\left(\frac{\partial N_{i}}{\partial \alpha}\right) \phi_{1 i} \\
& B_{N L}(9,5)=2\left(\frac{\partial N_{i}}{\partial \alpha}\right) \phi_{2 i} \\
& B_{N L}(9,6)=2\left(\frac{\partial N_{i}}{\partial \alpha}\right) u_{i} \\
& B_{N L}(9,7)=2\left(\frac{\partial N_{i}}{\partial \alpha}\right) v_{i} \\
& B_{N L}(10,1)=\left(\frac{\partial N_{i}}{\partial \beta}\right) \psi_{1 i} \\
& B_{N L}(10,2)=\left(\frac{\partial N_{i}}{\partial \beta}\right) \psi_{2 i} \\
& B_{N L}(10,3)=2 \frac{\psi_{2 i}}{R_{2}} \\
& B_{N L}(10,4)=2\left(\frac{\partial N_{i}}{\partial \beta}\right) \phi_{1 i} \\
& B_{N L}(9,5)=2\left(\frac{\partial N_{i}}{\partial \beta}\right) \phi_{2 i} \\
& B_{N L}(10,6)=2\left(\frac{\partial N_{i}}{\partial \beta}\right) u_{i} \\
& B_{N L}(10,7)=2\left(\frac{\partial N_{i}}{\partial \beta}\right) v_{i} \\
& B_{N L}(11,1)=\left(\frac{\partial N_{i}}{\partial \alpha}\right)^{2} \psi_{1 i}+\left(\frac{\psi_{1 i}}{R_{1}^{2}}\right) \\
& B_{N L}(11,2)=\left(\frac{\partial N_{i}}{\partial \alpha}\right)^{2} \psi_{2 i} \\
& B_{N L}(11,3)=2\left(\frac{\partial N_{i}}{\partial \alpha}\right)\left(\frac{\psi_{1 i}}{R_{1}}\right) \\
& B_{N L}(11,4)=\left(\frac{\partial N_{i}}{\partial \alpha}\right)^{2} \phi_{1 i}+\left(\frac{\phi_{1 i}}{R_{1}^{2}}\right) \\
& B_{N L}(11,5)=\left(\frac{\partial N_{i}}{\partial \alpha}\right)^{2} \phi_{2 i} \\
& B_{N L}(11,6)=\left(\frac{\partial N_{i}}{\partial \alpha}\right)^{2} u_{i}-\left(\frac{\partial N_{i}}{\partial \alpha}\right)\left(\frac{w_{i}}{R_{1}}\right) \\
& B_{N L}(11,7)=\left(\frac{\partial N_{i}}{\partial \alpha}\right)^{2} v_{i} \\
& B_{N L}(12,1)=\left(\frac{\partial N_{i}}{\partial \beta}\right)^{2} \psi_{1 i} \\
& B_{N L}(12,2)=\left(\frac{\partial N_{i}}{\partial \beta}\right)^{2} \psi_{2 i}-\left(\frac{\psi_{2 i}}{R_{2}^{2}}\right) \\
& B_{N L}(12,4)=\left(\frac{\partial N_{i}}{\partial \beta}\right)^{2} \phi_{1 i} \\
& B_{N L}(12,5)=\left(\frac{\partial N_{i}}{\partial \beta}\right)^{2} \phi_{2 i}+\left(\frac{\phi_{2 i}}{R_{2}^{2}}\right) \\
& B_{N L}(12,6)=\left(\frac{\partial N_{i}}{\partial \beta}\right)^{2} u_{i} \\
& B_{N L}(12,7)=\left(\frac{\partial N_{i}}{\partial \beta}\right)^{2} v_{i}-\left(\frac{\partial N_{i}}{\partial \beta}\right)\left(\frac{w_{i}}{R_{2}}\right) \\
& B_{N L}(13,1)=2\left(\frac{\partial N_{i}}{\partial \alpha}\right)\left(\frac{\partial N_{i}}{\partial \beta}\right) \psi_{1 i}-\left(\frac{\psi_{2 i}}{R_{1} R_{2}}\right)
\end{aligned}
$$




$$
\begin{aligned}
& B_{N L}(13,2)=2\left(\frac{\partial N_{i}}{\partial \alpha}\right)\left(\frac{\partial N_{i}}{\partial \beta}\right) \psi_{2 i}-\left(\frac{\psi_{1 i}}{R_{1} R_{2}}\right) \\
& B_{N L}(13,4)=2\left(\frac{\partial N_{i}}{\partial \alpha}\right)\left(\frac{\partial N_{i}}{\partial \beta}\right) \phi_{1 i}+\left(\frac{\phi_{1 i}}{R_{1} R_{2}}\right) \\
& B_{N L}(13,5)=2\left(\frac{\partial N_{i}}{\partial \alpha}\right)\left(\frac{\partial N_{i}}{\partial \beta}\right) \phi_{2 i}+\left(\frac{\phi_{1 i}}{R_{1} R_{2}}\right) \\
& B_{N L}(13,6)=2\left(\frac{\partial N_{i}}{\partial \alpha}\right)\left(\frac{\partial N_{i}}{\partial \beta}\right) u_{i}-\left(\frac{\partial N_{i}}{\partial \beta}\right)\left(\frac{w_{i}}{R_{1}}\right) \\
& B_{N L}(13,7)=2\left(\frac{\partial N_{i}}{\partial \alpha}\right)\left(\frac{\partial N_{i}}{\partial \beta}\right) v_{i}-\left(\frac{\partial N_{i}}{\partial \alpha}\right)\left(\frac{w_{i}}{R_{2}}\right) \\
& B_{N L}(14,1)=3\left(\frac{\partial N_{i}}{\partial \alpha}\right) \theta_{1 i} \\
& B_{N L}(14,3)=3 \frac{\theta_{1 i}}{R_{1}} \\
& B_{N L}(14,5)=3\left(\frac{\partial N_{i}}{\partial \alpha}\right) \psi_{2 i} \\
& B_{N L}(14,2)=3\left(\frac{\partial N_{i}}{\partial \alpha}\right) \theta_{2 i} \\
& B_{N L}(14,4)=3\left(\frac{\partial N_{i}}{\partial \alpha}\right) \psi_{1 i} \\
& B_{N L}(14,6)=3\left(\frac{\partial N_{i}}{\partial \alpha}\right) \phi_{1 i} \\
& B_{N L}(14,7)=3\left(\frac{\partial N_{i}}{\partial \alpha}\right) \phi_{2 i} \\
& B_{N L}(14,8)=3\left(\frac{\partial N_{i}}{\partial \alpha}\right) u_{i} \\
& B_{N L}(14,9)=3\left(\frac{\partial N_{i}}{\partial \alpha}\right) v_{i} \\
& B_{N L}(15,1)=3\left(\frac{\partial N_{i}}{\partial \beta}\right) \theta_{1 i} \\
& B_{N L}(15,2)=3\left(\frac{\partial N_{i}}{\partial \beta}\right) \theta_{2 i} \\
& B_{N L}(15,3)=3 \frac{\theta_{2 i}}{R_{2}} \\
& B_{N L}(15,4)=3\left(\frac{\partial N_{i}}{\partial \beta}\right) \psi_{1 i} \\
& B_{N L}(15,5)=3\left(\frac{\partial N_{i}}{\partial \beta}\right) \psi_{2 i} \\
& B_{N L}(15,6)=3\left(\frac{\partial N_{i}}{\partial \beta}\right) \phi_{1 i} \\
& B_{N L}(15,7)=3\left(\frac{\partial N_{i}}{\partial \beta}\right) \phi_{2 i} \\
& B_{N L}(15,8)=3\left(\frac{\partial N_{i}}{\partial \beta}\right) u_{i} \\
& B_{N L}(15,4)=3\left(\frac{\partial N_{i}}{\partial \beta}\right) v_{i} \\
& B_{N L}(16,1)=\left(\frac{\partial N_{i}}{\partial \alpha}\right)^{2} \theta_{1 i}+\left(\frac{\theta_{1 i}}{R_{1}^{2}}\right) \\
& B_{N L}(16,2)=\left(\frac{\partial N_{i}}{\partial \alpha}\right)^{2} \theta_{2 i} \\
& B_{N L}(16,4)=\left(\frac{\partial N_{i}}{\partial \alpha}\right)^{2} \psi_{1 i}+\left(\frac{\psi_{1 i}}{R_{1}^{2}}\right) \\
& B_{N L}(16,5)=\left(\frac{\partial N_{i}}{\partial \alpha}\right)^{2} \psi_{2 i}
\end{aligned}
$$




$$
\begin{aligned}
& B_{N L}(16,6)=\left(\frac{\partial N_{i}}{\partial \alpha}\right)^{2} \phi_{1 i}+\left(\frac{\phi_{1 i}}{R_{1}^{2}}\right) \\
& B_{N L}(16,7)=\left(\frac{\partial N_{i}}{\partial \alpha}\right)^{2} \phi_{2 i} \\
& B_{N L}(16,8)=\left(\frac{\partial N_{i}}{\partial \alpha}\right)^{2} u_{i}-\left(\frac{\partial N_{i}}{\partial \alpha}\right)\left(\frac{w_{i}}{R_{1}}\right) \\
& B_{N L}(16,9)=\left(\frac{\partial N_{i}}{\partial \alpha}\right)^{2} v_{i} \\
& B_{N L}(17,1)=\left(\frac{\partial N_{i}}{\partial \beta}\right)^{2} \theta_{1 i} \\
& B_{N L}(17,2)=\left(\frac{\partial N_{i}}{\partial \beta}\right)^{2} \theta_{2 i}+\left(\frac{\theta_{2 i}}{R_{2}^{2}}\right) \\
& B_{N L}(17,4)=\left(\frac{\partial N_{i}}{\partial \beta}\right)^{2} \psi_{1 i} \\
& B_{N L}(17,5)=\left(\frac{\partial N_{i}}{\partial \beta}\right)^{2} \psi_{2 i}+\left(\frac{\psi_{2 i}}{R_{2}^{2}}\right) \\
& B_{N L}(17,6)=\left(\frac{\partial N_{i}}{\partial \beta}\right)^{2} \phi_{1 i} \\
& B_{N L}(17,7)=\left(\frac{\partial N_{i}}{\partial \beta}\right)^{2} \phi_{2 i}+\left(\frac{\phi_{2 i}}{R_{2}^{2}}\right) \\
& B_{N L}(17,8)=\left(\frac{\partial N_{i}}{\partial \beta}\right)^{2} u_{i} \\
& B_{N L}(17,9)=\left(\frac{\partial N_{i}}{\partial \beta}\right)^{2} v_{i}-\left(\frac{\partial N_{i}}{\partial \beta}\right)\left(\frac{w_{i}}{R_{2}}\right) \\
& B_{N L}(18,1)=2\left(\frac{\partial N_{i}}{\partial \alpha}\right)\left(\frac{\partial N_{i}}{\partial \beta}\right) \theta_{1 i}-\left(\frac{\theta_{2 i}}{R_{1} R_{2}}\right) \\
& B_{N L}(18,2)=2\left(\frac{\partial N_{i}}{\partial \alpha}\right)\left(\frac{\partial N_{i}}{\partial \beta}\right) \theta_{2 i}-\left(\frac{\theta_{2 i}}{R_{1} R_{2}}\right) \\
& B_{N L}(18,3)=\left(\frac{\partial N_{i}}{\partial \beta}\right)\left(\frac{\theta_{1 i}}{R_{1}}\right)-\left(\frac{\partial N_{i}}{\partial \beta}\right)\left(\frac{\theta_{2 i}}{R_{1}}\right) \\
& B_{N L}(18,4)=2\left(\frac{\partial N_{i}}{\partial \alpha}\right)\left(\frac{\partial N_{i}}{\partial \beta}\right) \psi_{1 i}+\left(\frac{\psi_{2 i}}{R_{1} R_{2}}\right) \\
& B_{N L}(18,5)=2\left(\frac{\partial N_{i}}{\partial \alpha}\right)\left(\frac{\partial N_{i}}{\partial \beta}\right) \psi_{2 i}+\left(\frac{\psi_{1 i}}{R_{1} R_{2}}\right) \\
& B_{N L}(18,6)=2\left(\frac{\partial N_{i}}{\partial \alpha}\right)\left(\frac{\partial N_{i}}{\partial \beta}\right) \phi_{1 i}+\left(\frac{\phi_{2 i}}{R_{1} R_{2}}\right) \\
& B_{N L}(18,7)=2\left(\frac{\partial N_{i}}{\partial \alpha}\right)\left(\frac{\partial N_{i}}{\partial \beta}\right) \phi_{2 i}+\left(\frac{\phi_{1 i}}{R_{1} R_{2}}\right) \\
& B_{N L}(18,8)=2\left(\frac{\partial N_{i}}{\partial \alpha}\right)\left(\frac{\partial N_{i}}{\partial \beta}\right) u_{i}-\left(\frac{\partial N_{i}}{\partial \beta}\right)\left(\frac{w_{i}}{R_{1}}\right)
\end{aligned}
$$




$$
\begin{aligned}
& B_{N L}(18,9)=2\left(\frac{\partial N_{i}}{\partial \alpha}\right)\left(\frac{\partial N_{i}}{\partial \beta}\right) v_{i}-\left(\frac{\partial N_{i}}{\partial \alpha}\right)\left(\frac{w_{i}}{R_{2}}\right) \\
& B_{N L}(19,4)=4\left(\frac{\partial N_{i}}{\partial \alpha}\right) \theta_{1 i} \\
& B_{N L}(19,5)=4\left(\frac{\partial N_{i}}{\partial \alpha}\right) \theta_{2 i} \\
& B_{N L}(19,6)=4\left(\frac{\partial N_{i}}{\partial \alpha}\right) \psi_{1 i} \\
& B_{N L}(19,7)=4\left(\frac{\partial N_{i}}{\partial \alpha}\right) \psi_{2 i} \\
& B_{N L}(19,8)=4\left(\frac{\partial N_{i}}{\partial \alpha}\right) \phi_{1 i} \\
& B_{N L}(19,9)=4\left(\frac{\partial N_{i}}{\partial \alpha}\right) \phi_{2 i} \\
& B_{N L}(20,4)=4\left(\frac{\partial N_{i}}{\partial \beta}\right) \theta_{1 i} \\
& B_{N L}(20,5)=4\left(\frac{\partial N_{i}}{\partial \beta}\right) \theta_{2 i} \\
& B_{N L}(20,6)=4\left(\frac{\partial N_{i}}{\partial \beta}\right) \psi_{1 i} \\
& B_{N L}(20,7)=4\left(\frac{\partial N_{i}}{\partial \beta}\right) \psi_{2 i} \\
& B_{N L}(20,8)=4\left(\frac{\partial N_{i}}{\partial \beta}\right) \phi_{1 i} \\
& B_{N L}(20,9)=4\left(\frac{\partial N_{i}}{\partial \beta}\right) \phi_{2 i} \\
& B_{N L}(21,4)=\frac{\theta_{1 i}}{R_{1}^{2}} \\
& B_{N L}(20,5)=\left(\frac{\partial N_{i}}{\partial \alpha}\right)^{2} \theta_{2 i} \\
& B_{N L}(21,6)=\left(\frac{\partial N_{i}}{\partial \alpha}\right)^{2} \psi_{1 i}+\left(\frac{\psi_{1 i}}{R_{1}^{2}}\right) \\
& B_{N L}(20,7)=\left(\frac{\partial N_{i}}{\partial \alpha}\right)^{2} \psi_{2 i} \\
& B_{N L}(21,8)=\left(\frac{\partial N_{i}}{\partial \alpha}\right)^{2} \phi_{1 i}+\left(\frac{\phi_{1 i}}{R_{1}^{2}}\right) \\
& B_{N L}(21,9)=\left(\frac{\partial N_{i}}{\partial \alpha}\right)^{2} \phi_{2 i} \\
& B_{N L}(22,4)=\left(\frac{\partial N_{i}}{\partial \beta}\right)^{2} \theta_{1 i} \\
& B_{N L}(22,5)=\left(\frac{\partial N_{i}}{\partial \beta}\right)^{2} \theta_{2 i}+\left(\frac{\theta_{2 i}}{R_{2}^{2}}\right) \\
& B_{N L}(22,6)=\left(\frac{\partial N_{i}}{\partial \beta}\right)^{2} \psi_{1 i} \\
& B_{N L}(22,7)=\left(\frac{\partial N_{i}}{\partial \beta}\right)^{2} \psi_{2 i}+\left(\frac{\psi_{2 i}}{R_{2}^{2}}\right) \\
& B_{N L}(22,8)=\left(\frac{\partial N_{i}}{\partial \beta}\right)^{2} \phi_{1 i} \\
& B_{N L}(23,4)=2\left(\frac{\partial N_{i}}{\partial \alpha}\right)\left(\frac{\partial N_{i}}{\partial \beta}\right) \theta_{1 i}+\left(\frac{\theta_{2 i}}{R_{1} R_{2}}\right) \\
& B_{N L}(23,5)=2\left(\frac{\partial N_{i}}{\partial \alpha}\right)\left(\frac{\partial N_{i}}{\partial \beta}\right) \theta_{2 i}-\left(\frac{\theta_{1 i}}{R_{1} R_{2}}\right) \\
& B_{N L}(23,6)=2\left(\frac{\partial N_{i}}{\partial \alpha}\right)\left(\frac{\partial N_{i}}{\partial \beta}\right) \psi_{1 i}-\left(\frac{\psi_{2 i}}{R_{1} R_{2}}\right) \\
& B_{N L}(22,8)=\left(\frac{\partial N_{i}}{\partial \beta}\right)^{2} \phi_{2 i}+\left(\frac{\phi_{2 i}}{R_{2}^{2}}\right)
\end{aligned}
$$




$$
\begin{aligned}
& B_{N L}(23,7)=2\left(\frac{\partial N_{i}}{\partial \alpha}\right)\left(\frac{\partial N_{i}}{\partial \beta}\right) \psi_{2 i}-\left(\frac{\psi_{1 i}}{R_{1} R_{2}}\right) \\
& B_{N L}(23,8)=2\left(\frac{\partial N_{i}}{\partial \alpha}\right)\left(\frac{\partial N_{i}}{\partial \beta}\right) \phi_{1 i}+\left(\frac{\phi_{2 i}}{R_{1} R_{2}}\right) \\
& B_{N L}(23,9)=2\left(\frac{\partial N_{i}}{\partial \alpha}\right)\left(\frac{\partial N_{i}}{\partial \beta}\right) \phi_{2 i}+\left(\frac{\phi_{1 i}}{R_{1} R_{2}}\right) \\
& B_{N L}(24,6)=5\left(\frac{\partial N_{i}}{\partial \alpha}\right) \theta_{1 i} \\
& B_{N L}(24,8)=5\left(\frac{\partial N_{i}}{\partial \alpha}\right) \psi_{1 i} \\
& B_{N L}(25,6)=5\left(\frac{\partial N_{i}}{\partial \beta}\right) \theta_{1 i} \\
& B_{N L}(25,8)=5\left(\frac{\partial N_{i}}{\partial \beta}\right) \psi_{1 i} \\
& B_{N L}(26,6)=\left(\frac{\partial N_{i}}{\partial \alpha}\right)^{2} \theta_{1 i}+\left(\frac{\theta_{1 i}}{R_{1}^{2}}\right) \\
& B_{N L}(26,8)=\left(\frac{\partial N_{i}}{\partial \alpha}\right)^{2} \psi_{1 i}+\left(\frac{\psi_{1 i}}{R_{1}^{2}}\right) \\
& B_{N L}(27,6)=\left(\frac{\partial N_{i}}{\partial \beta}\right)^{2} \theta_{1 i} \\
& B_{N L}(27,8)=\left(\frac{\partial N_{i}}{\partial \beta}\right)^{2} \psi_{1 i} \\
& B_{N L}(28,6)=2\left(\frac{\partial N_{i}}{\partial \alpha}\right)\left(\frac{\partial N_{i}}{\partial \beta}\right) \theta_{1 i}+\left(\frac{\theta_{2 i}}{R_{1} R_{2}}\right) \\
& B_{N L}(28,7)=2\left(\frac{\partial N_{i}}{\partial \alpha}\right)\left(\frac{\partial N_{i}}{\partial \beta}\right) \theta_{2 i}+\left(\frac{\theta_{1 i}}{R_{1} R_{2}}\right) \\
& B_{N L}(28,8)=2\left(\frac{\partial N_{i}}{\partial \alpha}\right)\left(\frac{\partial N_{i}}{\partial \beta}\right) \psi_{1 i}+\left(\frac{\psi_{2 i}}{R_{1} R_{2}}\right) \\
& B_{N L}(28,9)=2\left(\frac{\partial N_{i}}{\partial \alpha}\right)\left(\frac{\partial N_{i}}{\partial \beta}\right) \psi_{2 i}+\left(\frac{\psi_{1 i}}{R_{1} R_{2}}\right) \\
& B_{N L}(29,8)=6\left(\frac{\partial N_{i}}{\partial \alpha}\right) \theta_{1 i} \\
& B_{N L}(24,7)=5\left(\frac{\partial N_{i}}{\partial \alpha}\right) \theta_{2 i} \\
& B_{N L}(24,9)=5\left(\frac{\partial N_{i}}{\partial \alpha}\right) \psi_{2 i} \\
& B_{N L}(25,7)=5\left(\frac{\partial N_{i}}{\partial \beta}\right) \theta_{2 i} \\
& B_{N L}(25,9)=5\left(\frac{\partial N_{i}}{\partial \beta}\right) \psi_{2 i} \\
& B_{N L}(26,7)=\left(\frac{\partial N_{i}}{\partial \alpha}\right)^{2} \theta_{2 i} \\
& B_{N L}(26,9)=\left(\frac{\partial N_{i}}{\partial \alpha}\right)^{2} \psi_{2 i} \\
& B_{N L}(27,7)=\left(\frac{\partial N_{i}}{\partial \beta}\right)^{2} \theta_{2 i}+\left(\frac{\theta_{2 i}}{R_{2}^{2}}\right) \\
& B_{N L}(27,9)=\left(\frac{\partial N_{i}}{\partial \beta}\right)^{2} \psi_{2 i}+\left(\frac{\psi_{2 i}}{R_{2}^{2}}\right) \\
& B_{N L}(29,9)=6\left(\frac{\partial N_{i}}{\partial \alpha}\right) \theta_{2 i}
\end{aligned}
$$




$$
\begin{array}{ll}
B_{N L}(30,8)=6\left(\frac{\partial N_{i}}{\partial \beta}\right) \theta_{1 i} & B_{N L}(30,9)=6\left(\frac{\partial N_{i}}{\partial \beta}\right) \theta_{2 i} \\
B_{N L}(31,8)=\left(\frac{\partial N_{i}}{\partial \alpha}\right)^{2} \theta_{1 i}+\left(\frac{\theta_{1 i}}{R_{1}^{2}}\right) & B_{N L}(31,9)=\left(\frac{\partial N_{i}}{\partial \alpha}\right)^{2} \theta_{1 i} \\
B_{N L}(32,8)=\left(\frac{\partial N_{i}}{\partial \beta}\right)^{2} \theta_{2 i} & B_{N L}(32,9)=\left(\frac{\partial N_{i}}{\partial \beta}\right)^{2} \theta_{2 i}+\left(\frac{\theta_{2 i}}{R_{2}^{2}}\right) \\
B_{N L}(33,8)=2\left(\frac{\partial N_{i}}{\partial \alpha}\right)\left(\frac{\partial N_{i}}{\partial \beta}\right) \theta_{1 i}+\left(\frac{\theta_{2 i}}{R_{1} R_{2}}\right) & \\
B_{N L}(33,9)=2\left(\frac{\partial N_{i}}{\partial \alpha}\right)\left(\frac{\partial N_{i}}{\partial \beta}\right) \theta_{2 i}+\left(\frac{\theta_{1 i}}{R_{1} R_{2}}\right) &
\end{array}
$$

